\title{
Prominin-1 Allows Prospective Isolation of Neural Stem Cells from the Adult Murine Hippocampus
}

\author{
Tara L. Walker, ${ }^{1}$ Ann Wierick, ${ }^{1 \star}$ Alex M. Sykes, ${ }^{2 \star}$ Ben Waldau, ${ }^{1}$ Denis Corbeil,${ }^{1,3}$ Peter Carmeliet, ${ }^{4,5}$ \\ and Gerd Kempermann ${ }^{1,6}$ \\ ${ }^{1}$ CRTD —Center for Regenerative Therapies Dresden, Technische Universität Dresden, 01307 Dresden, Germany, ${ }^{2}$ Max Planck Institute for Molecular Cell \\ Biology and Genetics, 01307 Dresden, Germany, ${ }^{3}$ Tissue Engineering Laboratories (BIOTEC), Technische Universität Dresden, 01307 Dresden, Germany, \\ ${ }^{4}$ Laboratory of Angiogenesis and Neurovascular Link, Vesalius Research Center, VIB, 3000 Leuven, Belgium, ${ }^{5}$ Laboratory of Angiogenesis and \\ Neurovascular Link, Vesalius Research Center, Department of Oncology, University of Leuven, 3000 Belgium, and ${ }^{6}$ German Center for Neurodegenerative \\ Diseases (DZNE), 01307 Dresden, Germany
}

Prominin-1 (CD133) is commonly used to isolate stem and progenitor cells from the developing and adult nervous system and to identify cancer stem cells in brain tumors. However, despite extensive characterization of Prominin- $1^{+}$precursor cells from the adult subventricular zone, no information about the expression of Prominin-1 by precursor cells in the subgranular zone (SGZ) of the adult hippocampus has been available. We show here that Prominin-1 is expressed by a significant number of cells in the SGZ of adult mice in vivo and ex vivo, including postmitotic astrocytes. A small subset of Prominin $-1^{+}$cells coexpressed the nonspecific precursor cell marker Nestin as well as GFAP and Sox2. Upon fluorescence-activated cell sorting, only Prominin-1/Nestin double-positive cells fulfilled the defining stem cell criteria of proliferation, self-renewal, and multipotentiality as assessed by a neurosphere assay. In addition, isolated primary Prominin $-1^{+}$cells preferentially migrated to the neurogenic niche in the SGZ upon transplantation in vivo. Finally, despite its expression by various stem and progenitor cells, Prominin-1 turned out to be dispensable for precursor cell proliferation in vitro and in vivo. Nevertheless, a net decrease in hippocampal neurogenesis, by $\sim 30 \%$ was found in Prominin- 1 knock-out mice, suggesting other roles in controlling adult hippocampal neurogenesis. Remarkably, an upregulation of Prominin-2 was detected in Prominin-1-deficient mice highlighting a potential compensatory mechanism, which might explain the lack of severe symptoms in individuals carrying mutations in the Prom 1 gene.

\section{Introduction}

By many standards Prominin-1 is considered one of the most valuable "neural stem cell markers." Based on Prominin-1 expression, stem cells can be prospectively isolated from the fetal (Uchida et al., 2000) and adult subventricular zone (SVZ) (Beckervordersandforth et al., 2010; Obermair et al., 2010), the postnatal cerebellum (Lee et al., 2005), and brain tumors (Singh et al., 2004). The function of Prominin-1, however, has not yet been fully unraveled and its role in the context of adult neurogenesis in the two "canonical" neurogenic zones of the adult brain, the SVZ of the

Received July 15, 2012; revised Nov. 27, 2012; accepted Dec. 19, 2012.

Author contributions: T.L.W., A.M.S., and G.K. designed research; T.L.W., A.W., A.M.S., and B.W. performed research; D.C. and P.C. contributed unpublished reagents/analytic tools; T.L.W., A.M.S., and G.K. analyzed data; T.L.W., D.C., and G.K. wrote the paper.

This work was supported by a Marie Curie International Incoming Fellowship (T.L.W.), the 2011 William P. Van Wagenen Fellowship Award from the American Association of Neurological Surgeons (B.W.), and by long-term structural funding - Methusalem funding by the Flemish Government — and by Grant FWO G.0209.07 of the Flemish Government (P.C.). This project was financed from basic institutional funding and partly with support from Priority Research Program (SFB) 655 to G.K. and D.C. We thank Anne Karasinsky for care and maintenance of all animals used in this study and Nicole Rund and Katja Schneider for assistance with FACS.

*A.W. and A.M.S. contributed equally to this work.

The authors declare no competing financial interests.

This article is freely available online through the J Neurosci Open Choice option.

Correspondence should be addressed to Dr. Tara Walker, CRTD — Center for Regenerative Therapies Dresden, Genomics of Regeneration, Fetscherstrasse 105, 01307 Dresden, Germany. E-mail: tara.walker@crt-dresden.de.

DOI:10.1523/JNEUROSCI.3363-12.2013

Copyright $\odot 2013$ the authors $\quad 0270-6474 / 13 / 333010-15 \$ 15.00 / 0$ lateral ventricles and the subgranular zone (SGZ) of the dentate gyrus in the hippocampal formation, remains unclear.

In the adult SVZ, astrocyte-like stem cells (B-cells) have a radial morphology, including an apical process bearing Prominin-1-expressing primary cilia (Beckervordersandforth et al., 2010). The SGZ of the dentate gyrus also contains a radial glia-like precursor cell (Type-1), but adult hippocampal neurogenesis has little in common with neurogenesis in the adult SVZ (Kempermann (2011), summarized in their Table 8-2). During development the stem cells for the future adult SGZ become displaced from the ventricular wall and form an ectopic germinative matrix. At least a subset of these cells is cilia bearing (Breunig et al., 2008), possibly suggesting the existence of a defined apical region, equivalent to the counterpart in the SVZ precursor cells. In a genetic association study we had found Prominin-1 expression in the brain to correlate with adult hippocampal neurogenesis in mice (Kempermann et al., 2006). Moreover, Prominin-1 was a cis-acting gene, and these genes are hypothesized to have strong, almost monogenic influences on the phenotypes with which they are associated. The question thus arose whether Prominin-1 would also be expressed by the stem cells of the SGZ as it is in the SVZ.

The unclear situation of hippocampal Prominin-1 expression was even more surprising given the considerable effort to identify specific cell-surface markers to prospectively isolate stem cell populations from the brain. Many combinations of markers have 
Table 1. Primers used in the present study

\begin{tabular}{|c|c|c|c|}
\hline Primer name & Gene target & Sequence $\left(5^{\prime}-3^{\prime}\right)$ & $\begin{array}{l}\text { Product length } \\
\text { (bp) }\end{array}$ \\
\hline$\beta$-actin- $F$ & $\beta$-actin & aaatcgtgcgtgacatcaaa & 178 \\
\hline$\beta$-actin-R & & aaggaaggctggaaaagagc & \\
\hline mProm2305F & Prominin-1 universal & tgaagaagatccttgcctc & 210 \\
\hline mProm2515R & & tccgcaacatagccacac & \\
\hline Prom2-629F & Prominin-2 & cacacacatagtcagacgg & 206 \\
\hline Prom2-835R & & gtacactgtgctcttgag & \\
\hline mProm56F & Prominin-1.s1 & ccgagacccggaggagagc & 477 \\
\hline mProm533R & & tagagggcaatctccttgg & \\
\hline mProm56F & Prominin-1.s2 & ccgagacccggaggagagc & 438 \\
\hline mProm494R & & gccaagactatgatttctgg & \\
\hline mProm2557F & Prominin- $1 . s 3 / 4 / 5$ or $s 6$ & tctgtgtggctatgttgcgg & 230 or 467 \\
\hline mProm2728R & & catgcatgttcaccagacac & \\
\hline mProm2236F & Prominin-1.s8 & gaaatttgtgagggtgagg & 418 \\
\hline mProm2654R & & cctctgaatccatcctgcg & \\
\hline
\end{tabular}

$F$, forward; $R$, reverse; bp, base pair.

now been described for the isolation of adult SVZ precursor cells, including Heat Stable Antigen/Peanut Agglutinin (Rietze et al., 2001), Sox2-GFP (Barraud et al., 2005; Brazel et al., 2005), Nestin-GFP (Mignone et al., 2004), EGF receptor (Ciccolini et al., 2005), GFAP/Lex/SSEA-1 (Imura et al., 2006), Prominin-1 (Corti et al., 2007), GFAP-GFP/EGF receptor/CD24 ${ }^{\text {low }}$ (Pastrana et al., 2009), and GFAP-GFP/Prominin-1 (Beckervordersandforth et al., 2010). In the dentate gyrus, the search for markers suitable for prospective isolation of precursor cells led to reporter-based strategies including DCX-GFP (Walker et al., 2007), Nestin-GFP (Gao et al., 2008), Hes5-GFP (Jhaveri et al., 2010), and Sox-2/DCX (Bracko et al., 2012), but none of these have yet made it to routine use.

We thus undertook the present study to resolve the question of Prominin-1-expression in the adult murine hippocampus and its usefulness to identify and prospectively isolate precursor cells of the SGZ.

\section{Materials and Methods}

Animals. C57BL/6 mice were originally obtained from Charles River. Prominin-1 ${ }^{-1-}$ mice (Zacchigna et al., 2009) were generated by Peter Carmeliet (Katholieke Universiteit, Leuven, Belgium), the TgN(GFAPEGFP)Fki-GFEA mice (Nolte et al., 2001) were generated by Frank Kirchhoff (University of Saarland, Homburg, Germany) and the NestinGFP mice (Yamaguchi et al., 2000) by Masuhiro Yamaguchi (University of Tokyo). The GFAP-GFP and Prominin-1 ${ }^{-1-}$ transgenic mice were kindly supplied by Wieland B. Huttner from a colony maintained at the Max Planck Institute for Cell Biology and Molecular Genetics. All experiments were conducted in accordance with the applicable European and National regulations (Tierschutzgesetz) and approved by the responsible authority (Regierungspräsidium Dresden). Animals were maintained on a $12 \mathrm{~h} \mathrm{light/dark} \mathrm{cycle} \mathrm{with} \mathrm{food} \mathrm{and} \mathrm{water} \mathrm{provided} \mathrm{ad} \mathrm{libitum.}$

Total RNA isolation, $c D N A$ synthesis, and quantitative PCR. Total RNA was isolated from postnatal day 2 (P2), P3, P5, P10, P15, P20, and P30 hippocampus using the RNeasy minikit (Qiagen) according to the manufacturer's instructions. Reverse transcription was performed to synthesize cDNA using the SuperScript II system (Invitrogen). Quantitative PCR (q-PCR) was performed using the SYBR Green qPCR Supermix (Invitrogen). q-PCR primers were designed to amplify regions of the Prominin-1 gene. The PCR program consisted of $95^{\circ} \mathrm{C}$ for $15 \mathrm{~min}$, followed by 45 cycles of $94^{\circ} \mathrm{C}$ for $15 \mathrm{~s}, 57^{\circ} \mathrm{C}$ for $30 \mathrm{~s}$, and $72^{\circ} \mathrm{C}$ for $30 \mathrm{~s}$. All gene amplification was standardized to a $\beta$-actin control. Gene expression was quantified as fold differences. Each sample was tested in triplicate, and data from at least three independent animals were used to calculate the means and SDs. The primer sequences can be found in Table 1.
Splice variant PCRs. Total RNA was isolated from the dentate gyrus, SVZ, and kidney of adult C57BL/6 mice and cDNA prepared, as described above. PCRs were performed with primers designed to discriminate between the various mouse Prominin-1 splice variants. PCRs were performed using the PCR SuperMix (Invitrogen) and the PCR cycling conditions were as follows: $94^{\circ} \mathrm{C}$ for $5 \mathrm{~min}$, followed by 35 cycles of $94^{\circ} \mathrm{C}$ for $30 \mathrm{~s}, 50^{\circ} \mathrm{C}$ for $30 \mathrm{~s}$, and $72^{\circ} \mathrm{C}$ for $30 \mathrm{~s}$. For the primer sequences and the splice variant they amplify see Table 1.

Brain tissue preparation. Wild-type C57BL/6, Nestin-GFP, or GFAPGFP mice ( 8 weeks old, males and females) were perfused transcardially with $0.9 \% \mathrm{NaCl}$ followed by $4 \%$ paraformaldehyde (PFA). The brains were then removed and postfixed in 4\% PFA overnight. After postfixation, the brains were cryoprotected by incubation overnight in $30 \% \mathrm{w} / \mathrm{v}$ sucrose in PBS until they sank. Frozen coronal serial sections $(40 \mu \mathrm{m})$ were cut from a dry-ice cooled copper stage at a Leica table-top sliding microtome and stored at $4^{\circ} \mathrm{C}$ in cryoprotectant solution (25\% ethylene glycol, $25 \%$ glycerol in $0.1 \mathrm{~m}$ phosphate buffer, $\mathrm{pH}$ 7.4).

Prominin-1 immunohistochemistry. For Prominin-1 staining, sections were first incubated for $60 \mathrm{~min}$ at room temperature with blocking solution: $10 \%$ normal donkey serum (NDS; Sigma-Aldrich) in $0.1 \mathrm{M}$ PBS containing $0.2 \%$ Saponin. The blocking solution was replaced with fresh solution containing 3\% NDS, $0.2 \%$ Saponin, and primary antibodies. The primary antibodies were as follows: rat monoclonal antibody $(\mathrm{mAb})$ 13A4 (1:250; a gift from Wieland B. Huttner), goat polyclonal Sox2 (1: 200; Santa Cruz Biotechnology), mouse monoclonal NeuN (1:100; Millipore Bioscience Research Reagents), rabbit polyclonal GFAP (1:500; DakoCytomation), and rabbit polyclonal Somatostatin 3 receptor (1: 500; Thermo Scientific). Following incubation overnight at $4^{\circ} \mathrm{C}$ the sections were then washed with PBS and incubated overnight at $4^{\circ} \mathrm{C}$ in blocking solution containing the appropriate DyLight secondary antibodies (1:1000; Dianova) or fluorescently conjugated wheat germ agglutinin Alexa Fluor 633 (1:1000; Invitrogen). After washing with PBS, the sections were mounted onto slides and coverslipped with fluorescence mounting medium (Dako). Images were captured using an LSM 700, $63 \times / 1.3$ NA glycerol objective (Carl Zeiss).

Fluorescence-activated cell sorting. C57BL/6, Nestin-GFP (Yamaguchi et al., 2000), or GFAP-GFP (Nolte et al., 2001) mice (8 weeks old; eight per experiment; males and females) were killed, their brains immediately removed, and the dentate gyri (Hagihara et al., 2009) and SVZ were microdissected. The tissue was enzymatically digested using the Neural Tissue Dissociation Kit (Miltenyi) according to the manufacturer's instructions. Following a final wash in HBSS (PAA; GE Healthcare) the pellet was resuspended in $1 \mathrm{ml}$ of HBSS and filtered through a $40 \mu \mathrm{m}$ cell sieve (Falcon; BD Biosciences). Cells were stained with a Prominin-1specific antibody (13A4-Phycoerythrin (PE); eBioscience) and/or the CD24-Allophycocyanin (APC) (eBioscience) for $30 \mathrm{~min}$ at $4^{\circ} \mathrm{C}$. Before adding the Prominin-1-PE or CD24-APC antibodies, a small proportion of the cells were removed and stained with an isotype control (Rat IgG1-PE or Rat IgG2bK-APC; eBioscience) as a control for nonspecific staining. The cells were finally washed in $10 \mathrm{ml}$ of HBSS before being resuspended in $1 \mathrm{ml}$ of HBSS for analysis by fluorescence-activated cell sorting (FACS). Cells were analyzed using a FACS Aria cell sorter (BD Biosciences). Dead cells were excluded by staining with propidium iodide $(1 \mu \mathrm{g} / \mathrm{ml})$.

Cell cycle analysis. Cell cycle analysis was performed on Prominin-1APC/Nestin-GFP stained cells using a combination of Pyronin Y (PY) and Hoechst 33342 to differentially stain DNA and RNA. Dentate gyri were dissected from eight Nestin-GFP mice (8 weeks old, males and females) and dissociated as described above. The cells were first washed in Hoechst staining buffer (HBSS containing 20 mm HEPES, pH 7.2, 1 $\mathrm{g} / \mathrm{L}$ glucose, $10 \%$ fetal bovine serum, and $100 \mu \mathrm{M}$ verapamil) then resuspended in staining buffer containing $1.6 \mu \mathrm{M}$ Hoechst 33342. Following incubation for $45 \mathrm{~min}$ at $37^{\circ} \mathrm{C}$ in the dark, $3.3 \mu \mathrm{M}$ PY was added and the cells incubated for a further $45 \mathrm{~min}$ at $37^{\circ} \mathrm{C}$. The cells were washed with $10 \mathrm{ml}$ of staining buffer and resuspended in $1 \mathrm{ml}$ of staining buffer containing $5 \mu \mathrm{l}$ of the Prominin-1-APC directly conjugated antibody and incubated at $4^{\circ} \mathrm{C}$ for $20 \mathrm{~min}$. Following a final wash the cells were resuspended in $0.5 \mathrm{ml}$ of staining buffer, passed through a $40 \mu \mathrm{m}$ sieve, and analyzed by flow cytometry. Control tubes with each of the fluoro- 
phores stained individually were prepared (unstained, Nestin-GFP, Prominin-1-APC, Hoechst 33342, and PY) to set the compensation values.

Neurosphere culture. Sorted populations of cells were collected directly into neurosphere growth medium and each population plated into 48 wells of a 96-well plate. Cells isolated from the Prominin-1 knock-out or wild-type mice were isolated and plated at a density of one SVZ or dentate gyrus per 96-well plate. The neurosphere growth medium consisted of mouse DMEM/F-12 basal medium (Gibco, Life Technologies) plus mouse NeuroCult NSC Proliferation Supplements (Stem Cell Technologies) with $2 \%$ bovine serum albumin (Gibco, Life Technologies), 2 $\mu \mathrm{g} / \mathrm{ml}$ heparin (Sigma-Aldrich), and a final $\mathrm{KCl}$ concentration of $15 \mathrm{~mm}$. The following growth factors were also included: $20 \mathrm{ng} / \mathrm{ml}$ purified mouse receptor-grade epidermal growth factor (EGF; BD Biosciences) and $10 \mathrm{ng} / \mathrm{ml}$ recombinant bovine FGF-2 (Roche). Cells were incubated in humidified $5 \% \mathrm{CO}_{2}$ for $7 \mathrm{~d}$ for SVZ or $12 \mathrm{~d}$ for dentate gyrus to permit neurosphere formation. Approximately $16 \mathrm{~h}$ after sorting the cells were counted in at least six wells and the average cell number per well was determined. For the Prominin-1 knock-out mice dentate gyrus and SVZ tissue were dissected and dissociated as described above and plated in neurosphere medium at a density of the dentate gyri or SVZ or one animal per 96-well plate.

Neurosphere passaging and differentiation. Primary hippocampal neurospheres were passaged by removing $150 \mu \mathrm{l}$ of the medium from wells containing single large neurospheres, and treating with $100 \mu \mathrm{l}$ of $0.05 \%$ trypsin- EDTA (Gibco) for 3 min room temperature, followed by washing with $100 \mu \mathrm{l}$ of trypsin inhibitor $(0.125 \mathrm{mg} / \mathrm{ml}$ trypsin inhibitor plus $0.01 \mathrm{mg} / \mathrm{ml}$ DNaseI) in DMEM. The neurospheres were mechanically triturated until dissociated and replated in 24-well plates in $2 \mathrm{ml}$ of complete medium. Neurospheres were passaged every $10 \mathrm{~d}$ by removing the medium containing the neurospheres from the plates and centrifuging at $100 \mathrm{rcf}$ for $7 \mathrm{~min}$. The supernatant was then decanted, and the neurospheres were incubated in $1 \mathrm{ml}$ of $0.05 \%$ trypsin-EDTA for $3 \mathrm{~min}$ at room temperature. After the addition of an equal volume of trypsin inhibitor, the neurospheres were centrifuged at $100 \times g$ for $7 \mathrm{~min}$ and the supernatant was removed. Cells were mechanically triturated in $500 \mu \mathrm{l}$ of complete medium and trypan blue staining was used to evaluate the number of cells, both viable and total number, on a hemocytometer. The passaged cells were then replated with complete medium at a density of $1 \times 10^{4} \mathrm{cells} / \mathrm{cm}^{2}$ in tissue culture flasks (Nalge Nunc International) or tissue culture plates (Falcon; BD Biosciences Discovery Labware) as appropriate. For differentiation, neurospheres were plated onto PDL and laminin-coated coverslips in DMEM/F-12 Basal Medium containing mouse NeuroCult NSC Proliferation Supplements without growth factors. The neurospheres were allowed to differentiate for $8 \mathrm{~d}$ in humidified $5 \% \mathrm{CO}_{2}$ until flattened and adherent. The differentiated neurospheres were then fixed with 4\% PFA in $0.1 \mathrm{M}$ PBS at room temperature for 30 min. After washing with PBS, they were stained for either the neuronal markers $\beta$ III-tubulin or Map2ab, the astrocytic marker GFAP, the oligodendrocyte marker $\mathrm{O} 4$, or the precursor cell antigen Nestin, with a 4,6diamidino-2-phenylindole (DAPI) counterstain to visualize the nuclei.

Adherent precursor cell line initiation and passaging. Cells from the dentate gyrus of eight adult C57BL/6 mice were prepared and sorted by flow cytometry as described above. The primary cells from each sorted population were plated into one well of a 24 -well plate (Falcon; BD Biosciences Discovery Labware) that had been coated with PDL (10 mg/ $\mathrm{ml}$ ) and laminin $(10 \mathrm{mg} / \mathrm{ml})$ in $2 \mathrm{ml}$ of growth medium. The growth medium consisted of Neurobasal medium (Gibco, Life Technologies), supplemented with 2\% B27 (Invitrogen), 1× GlutaMAX (Life Technologies), and $50 \mathrm{U} / \mathrm{ml}$ penicillin/streptomycin (Life Technologies). As growth factors $20 \mathrm{ng} / \mathrm{ml} \mathrm{EGF}$ and $20 \mathrm{ng} / \mathrm{ml} \mathrm{FGF-2} \mathrm{were} \mathrm{added} \mathrm{for} \mathrm{pro-}$ liferation conditions. The growth medium was changed every $2-3 \mathrm{~d}$ and the cells passaged when they reached $\sim 80 \%$ confluency.

Immunostaining of neurospheres and adherent cultures. The differentiated neurospheres or adherent cultures were fixed with 4\% PFA (SigmaAldrich) in $0.1 \mathrm{M}$ PBS at room temperature for $20 \mathrm{~min}$. After washing with PBS, the cells were incubated in blocking solution (10\% NDS in 0.1 M PBS containing $0.2 \%$ Triton X-100) for $60 \mathrm{~min}$ at room temperature. The cells were then incubated in fresh blocking solution containing mouse monoclonal $\beta$ III-tubulin antibody (1:2000; Promega) plus rabbit polyclonal GFAP antibody (1:500; DakoCytomation) for $60 \mathrm{~min}$ at room temperature. The cells were washed three times with PBS and incubated in fresh blocking solution containing donkey anti-mouse Cy3 antibody (1:1000; Jackson ImmunoResearch), DyLight 488 donkey anti-rabbit antibody (1:1000; Dianova), and DAPI (1:5000; Sigma-Aldrich) for $30 \mathrm{~min}$ at room temperature. Following another three PBS washes, the slides were mounted using fluorescence mounting medium (DakoCytomation) before being viewed on a Zeiss Apotome microscope.

In vivo transplantation of Prominin $-1^{+}$precursor cells. The dentate gyri from eight transgenic $\beta$-actin-GFP mice were dissected, dissociated, and stained with the Prominin-1-PE antibody as described above. The Prominin $-1^{+}$and Prominin- ${ }^{-}$cells were isolated by FACS and collected into $5 \mu \mathrm{l}$ of proliferation medium. Adult C57BL/6 mice were anesthetized via intraperitoneal injection of ketamine $(50 \mathrm{mg} / \mathrm{kg})$ and xylazine $(8 \mathrm{mg} / \mathrm{kg})$, mounted onto a stereotaxic frame (Stoelting), and a $1.5 \mathrm{~cm}$ skin incision was made to expose the skull. A hole was drilled in the skull directly above the dentate gyrus. Using a syringe (Hamilton) connected to a 30 gauge needle, two injections of $1 \mu \mathrm{l}$ of the cellcontaining medium were performed per hemisphere (anterior/posterior -1.3 , medial/lateral $+/-1.0$, dorsal/ventral -2.2 ; anterior/posterior -2 , medial/lateral $+/-1.2$, dorsal/ventral -2.2 relative to bregma), Following overnight recovery in the home cage the mice were transferred to a large cage $\left(1 \mathrm{~m}^{2}\right.$ floor area) containing environmental enrichment for $6 \mathrm{~d}$, after which the mice were perfused and microtome sections were cut and stained for DCX, GFAP, Sox 2, NeuN, Olig2, NG2, or A2B5 as described above.

Bromodeoxyuridine injection. To assess cell proliferation or neuronal survival in the neurogenic regions, Prominin- $1^{+/+}$, Prominin $-1^{+/-}$and Prominin- $1^{-1-}$ mice ( 8 weeks old, males and females) were given a single intraperitoneal injection of $50 \mathrm{mg} / \mathrm{kg}$ bromodeoxyuridine (BrdU; Sigma) and perfused either $2 \mathrm{~h}$ (proliferation) or $28 \mathrm{~d}$ later (neuronal survival).

Tissue processing and BrdU immunohistochemistry. For immunohistochemistry, every sixth section was processed with BrdU immunohistochemistry. To assess proliferation, the sections were first washed thoroughly in TBS to remove the cryoprotectant solution. Pretreatment then consisted of incubations in $0.6 \% \mathrm{H}_{2} \mathrm{O}_{2}$ for $30 \mathrm{~min}$, washing with TBS and $0.9 \% \mathrm{NaCl}$, followed by DNA denaturation with $2.5 \mathrm{~N} \mathrm{HCl}$ for $30 \mathrm{~min}$ at $37^{\circ} \mathrm{C}$. The sections were then washed in PBS and incubated in blocking solution containing 10\% NDS and $0.2 \%$ Triton X-100 in TBS for $60 \mathrm{~min}$ at room temperature followed by incubation overnight at $4^{\circ} \mathrm{C}$ with a BrdU primary antibody (1:500; BD Bioscience) in blocking solution containing $3 \%$ NDS and $0.2 \%$ Triton X-100. The following day the sections were washed in PBS three times for $10 \mathrm{~min}$, blocked for $30 \mathrm{~min}$, and subsequently incubated for $2 \mathrm{~h}$ at room temperature with an anti-rat biotin secondary antibody (1:250; Jackson ImmunoResearch), diluted in blocking solution. diaminobenzidine detection was performed using the VECTASTAIN Elite ABC kit (Vector Laboratories) as per the manufacturer's instructions. After mounting in $0.1 \mathrm{M}$ phosphate buffer onto gelatin-coated object slides, the sections were air dried and incubated in Neo-Clear (Merck Millipore) for $90 \mathrm{~min}$. Coverslips were mounted using Neo-Mount (Merck Millipore) and dried at room temperature.

To assess net neuronal survival sections from mice injected with BrdU and killed $28 \mathrm{~d}$ later were processed for fluorescence staining with BrdU and Fox3 (NeuN). The sections were washed in PBS and incubated in blocking solution containing $10 \%$ NDS and $0.2 \%$ Triton X-100 in TBS for $60 \mathrm{~min}$ at room temperature followed by incubation overnight at $4^{\circ} \mathrm{C}$ with the BrdU (1:500; BD Bioscience) and NeuN (Fox3, 1:1000; Abcam) primary antibodies in blocking solution containing $3 \%$ NDS and $0.2 \%$ Triton X-100. The following day the sections were washed in PBS three times for $10 \mathrm{~min}$, blocked for $30 \mathrm{~min}$, and subsequently incubated for $4 \mathrm{~h}$ at room temperature with an anti-rat Alexa Fluor 488 and an anti-rabbit Cy3 secondary antibody (1:500; Jackson ImmunoResearch), diluted in blocking solution. Following three subsequent washes in PBS the sections were mounted onto glass slides using fluorescence mounting medium (DakoCytomation).

Data analysis. Data analysis was performed using Prism software (Version 4.0c, GraphPad Software). Results were expressed as mean \pm SEM. 
A

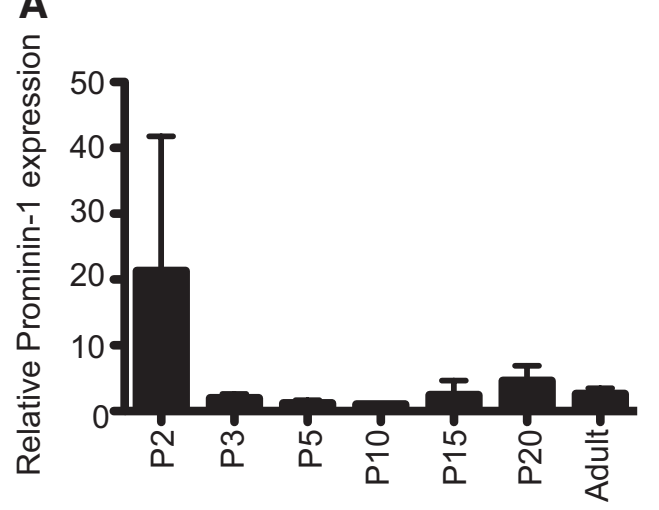

B

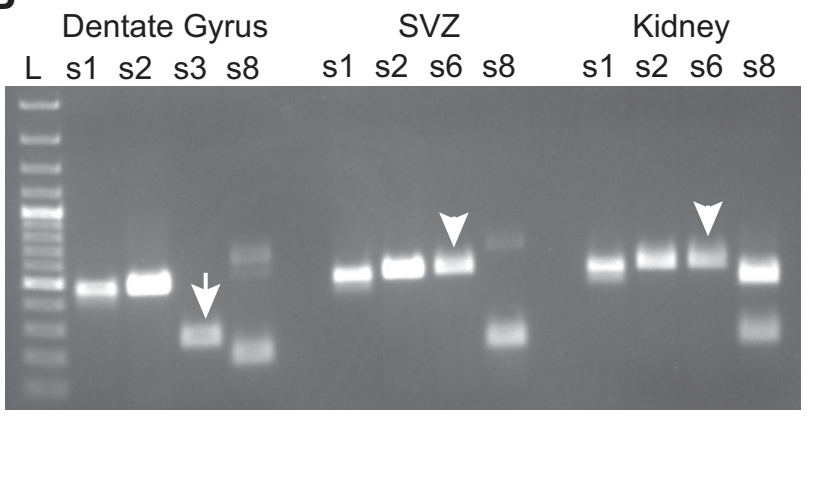

Figure 1. Prominin-1 is expressed in the developing and adult hippocampus. $\boldsymbol{A}, \mathrm{q}-\mathrm{PCR}$ analysis revealed the relative Prominin-1 expression in the developing hippocampus from $\mathrm{P} 2$ until adulthood. Data represent the mean \pm SEM ( $n=4$ independent animals per age group, not significant change in relative Prominin-1 expression with age; one-way ANOVA). $\boldsymbol{B}$, Distinct Prominin-1 splice variants are expressed in the dentate gyrus and SVZ. PCRs were performed using CDNAs prepared from adult dentate gyrus, SVZ, and kidney as templates with specific sets of Prominin-1 primers. 51 to s8 refer to a given Prominin-1 splice variant. Arrow and arrowhead indicate s3 and s6 variants, respectively. L, 100 bp molecular weight ladder.

Statistical significance was determined using one-way or two-way ANOVA with a Tukey's post hoc test or Student's $t$ tests as appropriate. The level of conventional statistical significance was set at $p \leq 0.05$.

\section{Results}

\section{Distinct splice variants of Prominin-1 are expressed in the} adult SGZ

To determine whether the Prom 1 gene is functional in the hippocampus we performed q-PCR using universal Prominin-1 primers designed to amplify all Prominin-1 splice variants identified to date (Fargeas et al., 2007). Interestingly, the comparison of the relative Prominin-1 expression at P2, P3, P5, P10, P15, P20, and adult revealed a stable expression of Prominin-1 transcripts in the maturing hippocampus from birth into adulthood (Fig. 1A).

The Prominin-1 transcript has a great propensity for alternative splicing (Fargeas et al., 2004) and to date, eight alternative murine splice variants have been characterized (Fargeas et al., 2007). The Prominin-1 N and C termini are the major structural domains subjected to splicing. Two of these splice variants, s1 and $s 3$, have previously been found in the adult mouse brain (Corbeil et al., 2009). In that study, it was shown that Prominin-1 s3 is expressed by cultured oligodendrocytes and might be a component of myelin, whereas the s1 variant is expressed by a subpopulation of GFAP-positive astrocytes (Corbeil et al., 2009). Using a combination of splice variant-specific primers we showed that a small facultative exon encoding 9 aa residues that could be either absent (e.g., s1 variant) or present (s2 variant) at the N-terminal domain (Yu et al., 2002) is detected in the adult SVZ, dentate gyrus, and kidney, suggesting that more than one splice variant can be simultaneously expressed (Fig. $1 B$ ). Interestingly, expression of the 56 variant, as defined by its C-terminal domain, appeared to be spatially restricted and could only be detected in the SVZ and kidney (Fig. $1 B$, arrowhead). In the dentate gyrus, the same primer pair could amplify only a smaller product corresponding to the C-terminal domain of either splice variant 3, 4, or 5 (Fig. $1 B$, arrow). The s8 variant, which to date has only been detected in the retina, could not be detected in either of the brain regions tested (Fig. $1 B$ ). Thus, particular areas of the adult brain (e.g., the dentate gyrus vs the SVZ) seem to express distinct Prominin-1 splice variants indicating a region-specific regulation of the Prom 1 gene.

Given that we could detect the Prominin-1 transcript in the adult hippocampus we next wanted to determine the tissue local- ization of Prominin-1 at a protein level using the 13A4 mAb. Following our standard protocols for immunohistochemistry we could clearly detect Prominin-1 in the ependymal cells of the adult SVZ (Fig. 2A), in agreement with previous reports (Beckervordersandforth et al., 2010), but its expression appeared absent from the dentate gyrus. Using a refined immunohistochemistry protocol, in which we substituted Saponin for Triton X-100 as a detergent (Röper et al., 2000), in fact revealed Prominin-1 staining in the two neurogenic regions, the SVZ and the SGZ, albeit at very different levels of intensity. In the dentate gyrus, the intensity of the Prominin-1 immunoreaction was very low and only detectable upon close examination at high magnification $(63 \times$; Fig. $2 B$ ). This pattern suggested that although Prominin-1 is expressed in both neurogenic zones of the adult brain, the levels of expression are considerably different between them. In addition, in the hippocampus the exact cell types that were Prominin- $1^{+}$were difficult to determine due to the discrete membrane compartmentalization of the Prominin-1 and the high cell density in the SGZ. We also stained hippocampal sections from Nestin-GFP and GFAPGFP transgenic mice with Prominin-1, which revealed Prominin-1 expression on both the Nestin ${ }^{+}$precursor cells (Fig. $2 C-E$ ) and on GFAP ${ }^{+}$"vertical" type-1 astrocytes or Type-1 cells (Fig. 2F). It has previously been shown that Prominin-1 is expressed by the cilia of astrocyte-like stem cells and ependymal cells of the SVZ (Beckervordersandforth et al., 2010). Using an antibody to detect the somatostatin receptor we were able to detect cilia-specific staining in the dentate gyrus (Fig. $2 F^{\prime \prime}$ ). However, the somatostatin receptor signal did not appear to colocalize with Prominin-1 staining in this region, indicating that in the dentate gyrus Prominin-1 is not expressed on the cilia. Colocalization of Prominin-1 expression with positive staining by the lectin wheat germ agglutinin, a carbohydrate binding protein that selectively recognizes sialic acid and $\mathrm{N}$-acetylglucosaminyl sugar residues predominantly found on plasma membranes, confirmed the localization of the Prominin-1 immunoreactivity on membrane rather than intermediate filaments (Fig. 2E).

Prominin-1 is not only associated with plasma membrane protrusions (e.g., microvilli, primary cilia, midbodies), but is also released into the extracellular milieu in association with small ( 80 $\mathrm{nm}$ in diameter $)$ or large $(\approx 600 \mathrm{~nm})$ membrane particles that originate from microvillus/primary cilium or midbody, respec- 

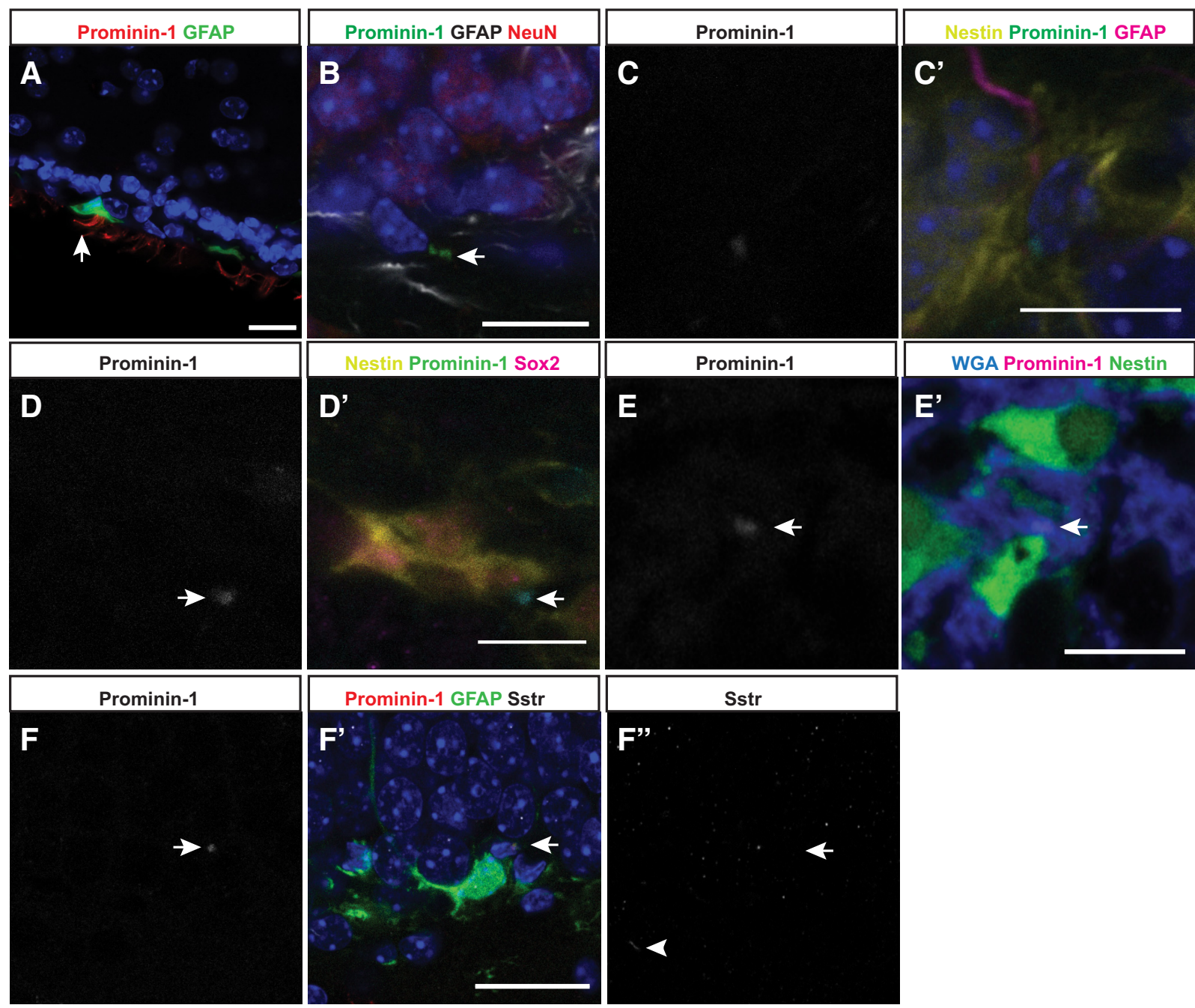

Figure 2. Prominin-1 is expressed in the adult SVZ and SGZ. Prominin-1 expression can be detected in the adult mouse SVZ (Prominin-1, red; GFAP, green; $A$ ) and SGZ (Prominin-1, green; GFAP, white; NeuN, red; $\boldsymbol{B}$ ). Prominin-1 is expressed in the precursor cells of the dentate gyrus as evidenced by colocalization with the precursor markers Nestin (yellow; $\boldsymbol{C}, \boldsymbol{D}), \mathrm{GFAP}$ (magenta; $\boldsymbol{C}$, and Sox2

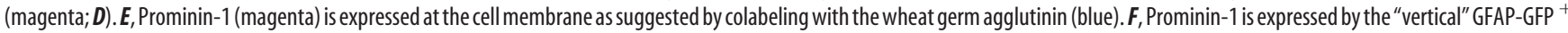
type-1 stem cells, but is not expressed on the cilium as evidenced by somatostatin receptor staining $\left(\boldsymbol{F}^{\prime \prime}\right)$. Arrows and arrowhead indicate Prominin-1 expression and somatostatin receptor $3\left(\right.$ Sstr3) ${ }^{+}$ cilium, respectively. Scale bars: $20 \mu \mathrm{m}$.

tively. The release of these Prominin-1-containing membrane particles occurs during the process of cellular differentiation. It therefore seemed possible that Prominin-1 could be found in small and large extracellular membrane particles since Prominin- $1^{+}$progenitor cells likely undergo a process of differentiation. However, the immunostaining of Prominin-1 that we detected (Fig. 2C-E') was different from one in cleaved midbodies, which should appear as a ring-like structure (Marzesco et al., 2005; Ettinger et al., 2011; Kuo et al., 2011). Moreover, both types of extracellular membrane particles that have been described are much smaller than the Prominin-1 immunoreactivity detected in our study $(1-3 \mu \mathrm{m})$.

Costaining of the Nestin-GFP sections with Prominin-1 in combination with another known stem cell marker, Sox2 (Fig. $2 E$ ), revealed that Prominin-1 is indeed expressed by the hippocampal precursor cells. A subset of Prominin- ${ }^{+}$cells in the dentate gyrus, however, was Nestin $^{-}$and expressed S100 $\beta$, a marker in the murine hippocampus found in postmitotic ("horizontal") astrocytes. In the SVZ, ependymal cells are also S100 $\beta$ positive (data not shown). Somewhat unexpectedly, a large number of $\mathrm{DCX}^{+} / \mathrm{Nestin}^{-}$(Type-3) cells in the SGZ also expressed Prominin-1 (data not shown).

\section{Concomitant detection of Prominin-1 and Nestin allows the} prospective isolation of hippocampal stem cells

Precursor cells can be prospectively isolated from the adult SVZ on the basis of coexpression of Prominin-1 and GFAP (Beckervordersandforth et al., 2010). This information, in combination with our detection of Prominin-1-expressing cells in the adult dentate gyrus, led us to next examine whether it would also be possible to prospectively isolate the hippocampal precursor cell population on the basis of Prominin-1. The dentate gyri from 8-week-old C57BL/6 mice were dissected, dissociated into a single-cell suspension, and stained with a PE-coupled Prominin-1 antibody. Dead cells and debris were excluded by gating the main cell population on the basis of forward and side scatter (Fig. 3A) and by staining with PI. The negative gates were set against unstained cells (Fig. $3 B$ ) and those cells stained with an isotype control (Fig. 3C). Importantly, we could confirm that the Prominin-1 antibody binding was specific; as cells isolated from 
A
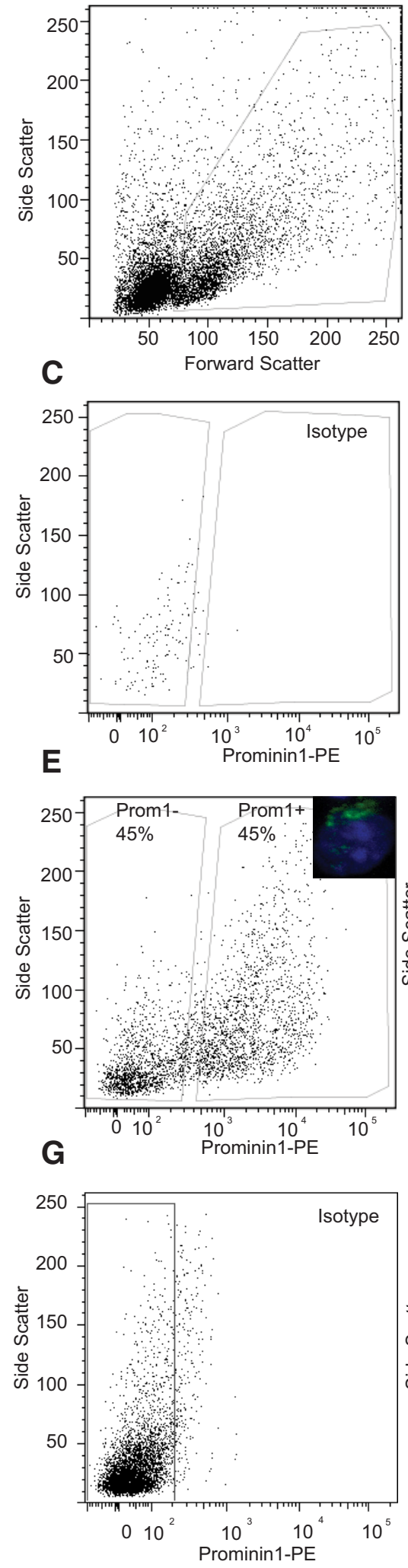

B
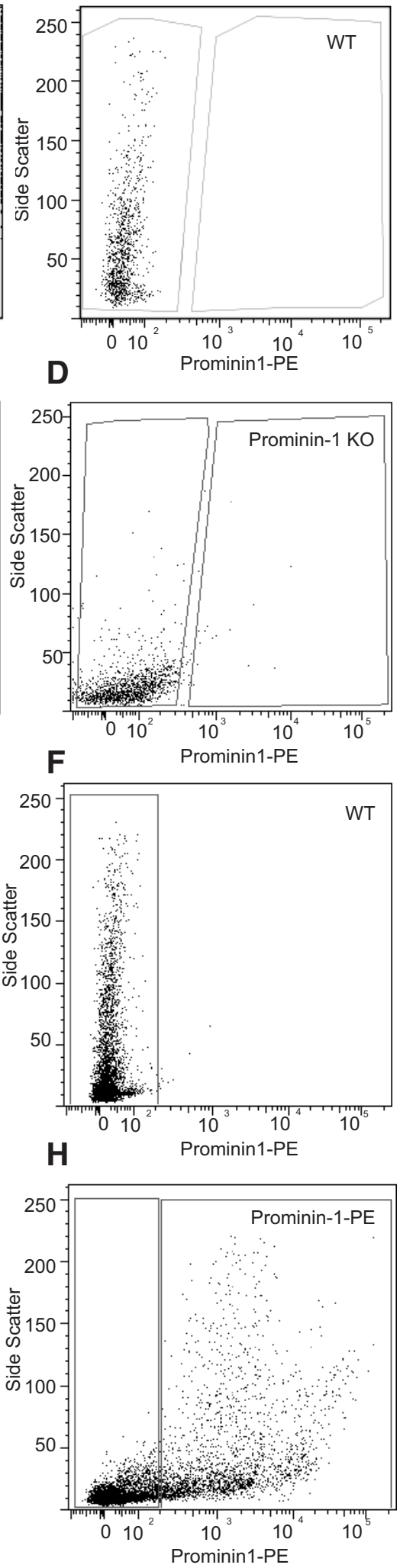

Figure 3. Prospective isolation of Prominin- ${ }^{+}$cells from the adult dentate gyrus and SVZ. A, FACS plot of the gating based on forward and side scatter. $\boldsymbol{B}$, The negative gate set by an unstained sample. $\boldsymbol{C}$, The lgG1-PE isotype control antibody was used for nonspecific binding of the Prominin-1-PE antibody. $\boldsymbol{D}$, Staining of cells derived from Prominin-1 knock-out (KO) mouse with the Prominin-1-PE antibody confirmed its specificity. E, Prominin-1 staining divides the cells into two approximately equal populations. $\boldsymbol{E}$, inset, Example of Prominin- ${ }^{+}$staining on a dissociated FAC sorted dentate gyrus cell. Following a gating strategy based on unstained $(\boldsymbol{F})$ and IgG1-PE isotype control stained $(\boldsymbol{G})$ cells $\sim 40 \%$ of cells in the adult SVZ are Prominin- $1^{+}(\boldsymbol{H})$. the dentate gyrus of Prominin-1 knockout mice showed no staining (Fig. 3D). Of the gated live cells $\sim 45 \%$ were labeled with Prominin-1 (Fig. 3E). The ability to accurately sort Prominin- $1^{+}$and Prominin- $1^{-}$cells was confirmed by immediately resorting each population. Both populations showed $>99 \%$ purity upon resorting.

Cells isolated from the adult SVZ were stained with the Prominin-1-PE antibody under the same conditions to compare the staining intensity and cell abundance of Prominin- $1^{+}$cells in the other major neurogenic region. When gated based on the unstained cells (Fig. $3 F$ ) and an isotype control (Fig. $3 G$ ) $\sim 40 \%$ of the SVZ cells stained positive for Prominin-1-PE (Fig. $3 H$ ). This Prominin- ${ }^{+}$cell frequency, as well as the relative staining intensity, was similar to cells isolated from the dentate gyrus.

Based on the immunohistochemical results in vivo, this large population of Prominin- $1^{+}$cells likely was heterogeneous, comprising a mix of stem and progenitor cells (Type-1 to -3) as well as astrocytes. The identity of the sorted Prominin- $1^{+}$cells was thus further analyzed with a number of cell-type-specific markers and flow cytometry. A large proportion $(\sim 70 \%)$ of the Prominin- $1^{+}$cells was positive for $S 100 \beta$, which for the SGZ would indicate a population of astrocytes lacking precursor cell properties. In addition, a large proportion of the Prominin1-expressing cells expressed GFAP and GLAST (45 and 75\%, respectively), proteins that are highly expressed in astrocytes, and the astrocyte-like precursor cells. Nestin was also expressed by a subset of Prominin- ${ }^{+}$cells indicating that the hippocampal precursor cells, as defined based on their Nestin-expression (Yamaguchi et al., 2000), also express Prominin-1.

To examine whether the Prominin- $1^{+}$ population contained the precursor cells, the sorted cell populations were grown under culture conditions, which enable single stem or progenitor cells to rapidly proliferate and form a large free-floating cluster of cells termed "neurosphere." Using the neurosphere-forming assay one can quantitatively estimate the number of precursor cells in a given cell population. To this end, cells were plated at a very low density ( $<100$ cells per well in a 96-well plate) and the number of neurospheres generated was quantified after $12 \mathrm{~d}$ of growth. Almost all of the neurospheres were formed from the Prominin $-1^{+}$population $(94.1 \pm 2.0 \%$ of the total neuro- 
spheres generated, $n=6$ experiments), whereas the sorted cells negative for Prominin-1 generated only very few neurospheres $(5.9 \pm 2.0 \%$ of the total neurospheres generated). Remarkably, the neurosphere-forming frequency of the Prominin $-1^{+}$population was $>30$-fold enriched compared with the negative population (Prominin- $1^{+}: 1$ in 115 cells, vs Prominin-1 ${ }^{-}$: 1 in 3704 cells).

To further purify the hippocampal precursor population, cells expressing Nestin-GFP were stained with Prominin1 -PE and sorted. First, the precursor specificity of the GFP in the Nestin-GFP transgenic mice was examined. Nestin ${ }^{+}$ cells constituted $\sim 8 \%$ of total cells and generated $80.6 \pm 16.5 \%$ of the total neurospheres ( $n=4$ experiments). Next, the Nestin-GFP cells were costained with the Prominin-1-PE antibody to determine whether colocalization of Nestin and Prominin-1 would further enrich the population of hippocampal precursor cells. The GFP gates were set based on a wild-type mouse (Fig. 4A) and staining with an isotype control antibody was used to set the PE gates (Fig. 4B). Four percent of all cells were positive for both Nestin and Prominin-1 (Fig. 4C). The growth of neurospheres from this small subset of cells confirmed that the majority of the neurosphere-forming cells were positive for both markers (70.9 \pm 10.7 neurospheres generated per 1000 Nestin $^{+} /$ Prominin $-1^{+}$cells) compared with the Nestin ${ }^{+}$-only and Prominin- ${ }^{+}$-only populations, which generated only a small number of neurospheres (Nestin ${ }^{+}$-only: $9.2 \pm 2.5$; Prominin- $1^{+}$-only: $1.2 \pm 0.3$ neurospheres per 1000 cells; Fig. 4D).

To confirm the specificity of Prominin-1 expression in the Prominin- $1^{+} /$Nestin $^{+}$ population compared with the Nestin ${ }^{+}$only population we examined the expression levels of the Prominin-1 splice variants s1 and s2 in these purified populations. Using the primer pairs mProm $189 \mathrm{~F} /$ mProm533R and mProm189F/mProm494R, we detected splice variants 1 and 2 in both populations. As expected, the doublepositive population had much greater expression of both splice variants amounting to an $\sim 7$-fold upregulation compared with the Nestin ${ }^{+} /$Prominin- $1^{-}$cells (relative increase: $6.9 \pm 4.5$-fold, $n=2$ individual FACS experiments, q-PCR triplicates). In addition, we confirmed that the Prominin$1^{+} / \mathrm{Nestin}^{+}$population was indeed highly enriched for Prominin-1 mRNA expression with a $>80$-fold enrichment compared with the Prominin ${ }^{-} / \mathrm{Nestin}^{-}$population (relative increase: $82.6 \pm 19.7$-fold, $n=2$
A

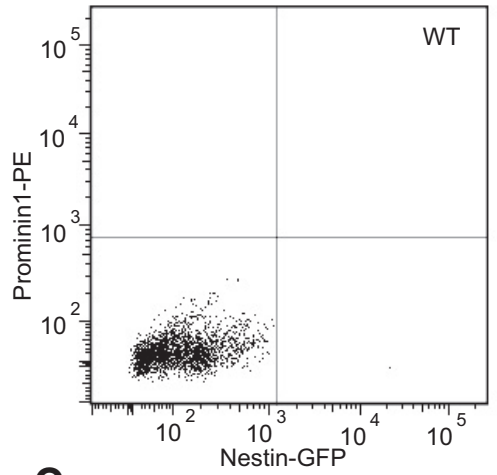

C
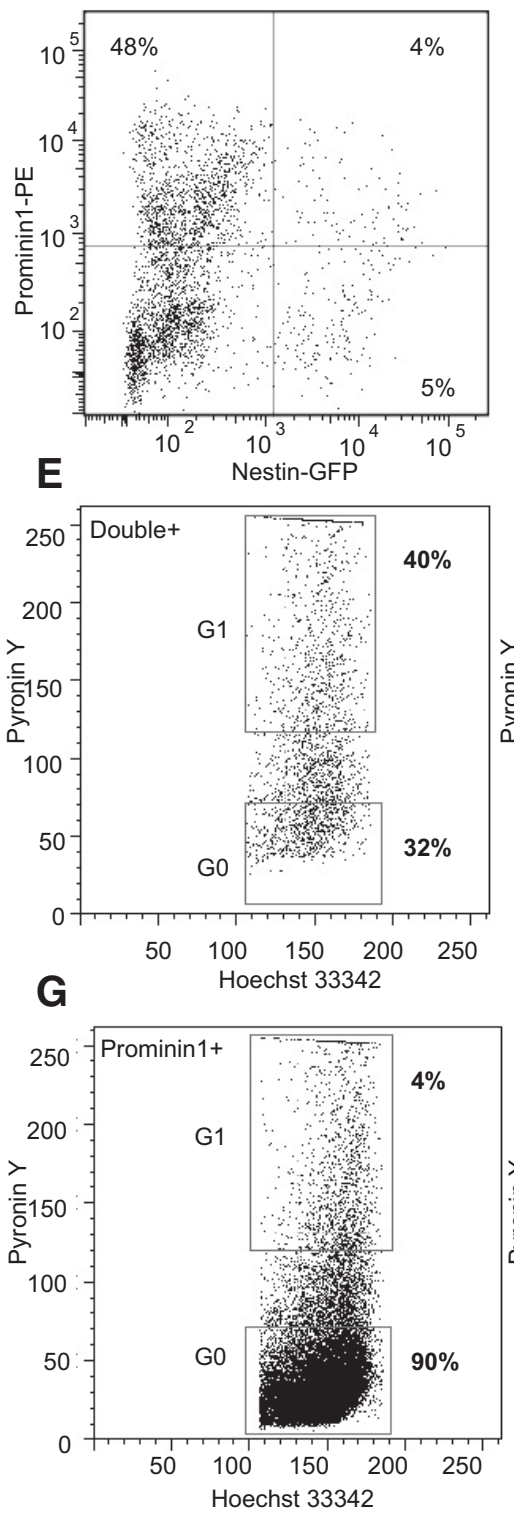

B

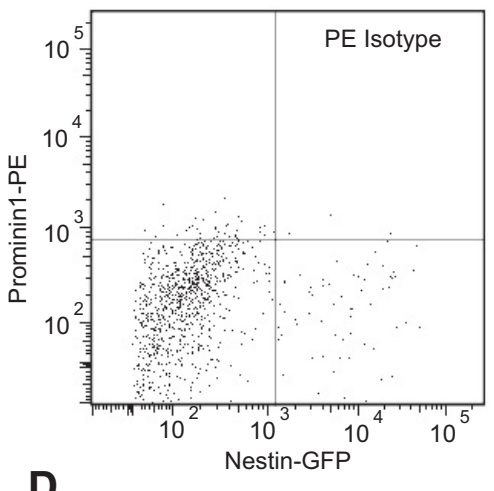

D

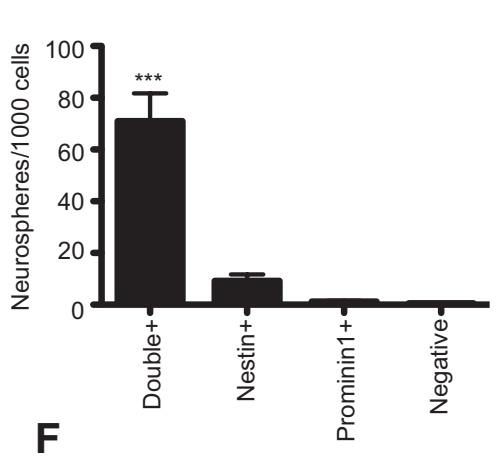

H

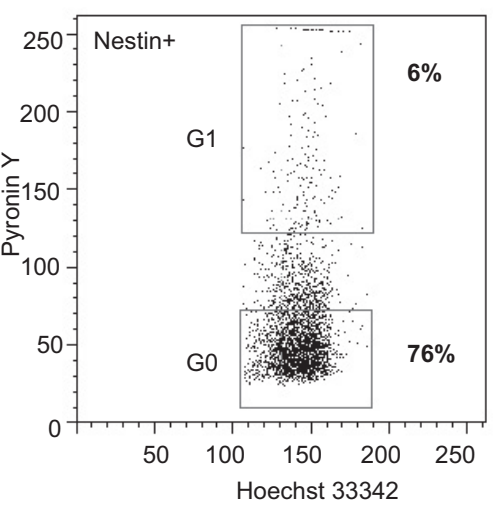

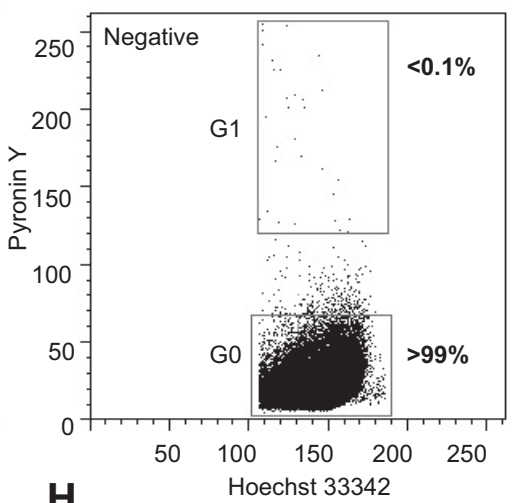

Figure 4. FACS isolation and neurosphere-forming potential of Nestin and Prominin-1 double-positive cells. $\boldsymbol{A}-\boldsymbol{C}$, Four cell populations based on the expression of Prominin- 1 and Nestin were isolated from Nestin-GFP transgenic mice by flow cytometry. $\boldsymbol{A}$, A wild-type (WT) littermate was used to set the GFP gates. $\boldsymbol{B}$, The lgG1-PE isotype control antibody was used to stain Nestin-GFP cells as a control for nonspecific PE binding. C, The FACS plot of the four populations gated based on Prominin-1-PE and Nestin-GFP expression. $\boldsymbol{D}$, A histogram representing the number of neurospheres that were generated per 1000 cells for each isolated population. Data represent the mean \pm SEM from three independent experiments, $F_{(8)}=37.7,{ }^{* * *} p \leq 0.001$, one-way ANOVA with Tukey's multiple-comparison test. Hoechst 33342/Pyronin Y cell cycle analysis on the Prominin- $1^{+} /$Nestin $^{+}(\boldsymbol{E})$, Prominin- ${ }^{-}$/ Nestin $^{-}(\boldsymbol{F})$, Prominin-1 ${ }^{+} /$Nestin $^{-}(\boldsymbol{G})$, and Prominin- $1^{-} /$Nestin $^{+}(\boldsymbol{H})$ sorted cell populations. 
individual FACS experiments, q-PCR triplicates).

As the neurosphere experiments were performed under proliferation conditions it is difficult to determine whether the Prominin- $1^{+} /$Nestin $^{+}$cell population contained the quiescent neural stem cells as well as the more highly proliferative progenitor cells. To address this we combined cell-surface staining (Prominin-1-APC staining of Nestin-GFP mice) with Hoechst 33342 and Pyronin Y staining. By staining with Hoechst and Pyronin $\mathrm{Y}$ we were able to differentiate between cells that were quiescent $\left(\mathrm{G}_{0}\right.$ : PY low) versus those that were cycling $\left(\mathrm{G}_{1}\right.$ : PY high). The Prominin-1/Nestin double-positive population described above amounted to only $\sim 4 \%$ of the total number of cells. In vivo a large number of the cells in this population were nondividing (quiescent) with $32 \%$ of the cells in the $\mathrm{G}_{0}$ phase as indicated by low levels of Pyronin Y staining (Fig. $4 E$ ). In addition, in accordance with our neurosphere data $\sim 40 \%$ of the cells in the Prominin $-1^{+} /$Nestin + population were actively dividing and stained strongly with the Pyronin Y dye. In contrast, the vast majority $(>99 \%)$ of the cells in the negative population was in the $G_{0}$ cell cycle phase and likely consisted of postmitotic neurons and astrocytes (Fig. 4F). The Prominin-1 and Nestin singlepositive populations also contained a small number of cycling cells ( 4 and $6 \%$, respectively), which are likely immature progenitor cells $\left(\mathrm{DCX}^{+}\right)$undergoing their last divisions and are not yet postmitotic (Fig. 4G,H).

\section{Precursor cell-containing fractions are not the highest in Prominin-1 expression}

Given the large and heterogeneous population of cells in the dentate gyrus that express Prominin-1, we divided the Prominin- ${ }^{+}$ cells into three subpopulations on the basis of their relative levels of Prominin-1 expression. Cells with high levels of Prominin-1 expression represented $\sim 8 \%$, intermediate (mid) $20 \%$ and low $15 \%$ of the total number of live cells (Fig. $5 A$ ). Interestingly, Prominin- $1^{\text {high }}$ cells did not generate any neurospheres (Fig. $5 B$ ) and all of the neurosphere-forming activity was found in the cells with lower levels of Prominin-1 (Prominin- ${ }^{\text {mid }}: 14.0 \pm 3.7$ neurospheres per 1000 cells; Prominin-1 ${ }^{\text {low }}: 28.1 \pm 4.3$ neurospheres per 1000 cells; Fig. 5B). When the neurosphere-forming frequency was expressed as a percentage of the total neurosphere number it became obvious that the majority of the neurospheres were generated from the Prominin- ${ }^{\text {mid }}$ population (Prominin$1^{\text {mid }}: 53 \pm 8.9 \%$ of total neurospheres formed; Prominin- $1^{\text {low }}$ : $42.9 \pm 8.0 \%$ of total neurospheres formed; Fig. $5 C$ ). The classification of neurospheres into four size categories (40-70, 80-120, $130-190$, and $\geq 200 \mu \mathrm{m}$ ) revealed no difference between those generated from Prominin-1 ${ }^{\text {mid }}$ and Prominin-1 ${ }^{\text {low }}$ subpopulations (no significant effect of cell population on neurosphere size in a two-way ANOVA $F_{(8)}=0.13, p=0.73, n=5$ individual FACS experiments; Fig. 5D).

As the Prominin- $1^{\text {high }}$ cells were not precursor cells, we next wanted to determine which other cell type would constitute the majority of that population. Using a combination of GFAP-GFP, the EGF receptor, and Heat Stable Antigen (CD24) it has been reported that astrocytes $\left(\mathrm{GFAP}^{+} \mathrm{EGFR}^{-} \mathrm{CD} 24^{-}\right)$, stem cells $\left(\mathrm{GFAP}^{+}\right.$ $\left.\mathrm{EGFR}^{+} \mathrm{CD} 24^{-}\right)$, transit-amplifying cells $\left(\mathrm{GFAP}^{-} \mathrm{EGFR}^{+} \mathrm{CD} 24^{-}\right)$, "neuroblasts" $\left(\mathrm{GFAP}^{-} \mathrm{EGFR}^{-} \mathrm{CD} 24^{\text {low }}\right)$, and ependymal cells $\left(\mathrm{GFAP}^{-} \mathrm{EGFR}^{-} \mathrm{CD} 24^{\text {high }}\right.$ ) can be simultaneously isolated from the adult SVZ (Pastrana et al., 2009). We thus made use of a similar strategy to determine the cell type that constituted the majority in each of the three Prominin-1 subpopulations of our experiment. We isolated the dentate gyrus from GFAP-GFP transgenic mice, stained the dissociated cells with both Prominin-1 and CD24, and charac-
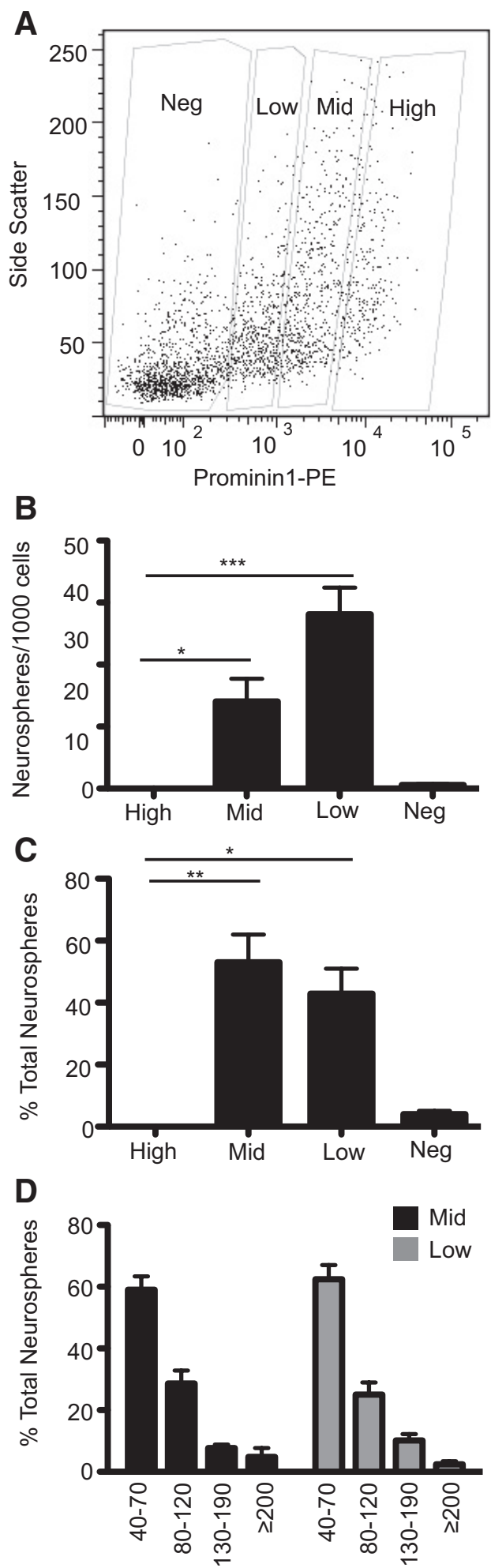

Figure 5. Three Prominin- $1^{+}$cell populations can be isolated based on Prominin-1 expression level. $\boldsymbol{A}$, The Prominin- ${ }^{+}{ }^{+}$cells were divided by flow cytometry into three populations on the basis of Prominin-1 expression level. $\boldsymbol{B}$, Histogram depicting the number of neurospheres formed per 1000 cells plated for each subpopulation. C, Histogram depicting the percentage of the total neurosphere number generated by each population. Data represent the mean $\pm S E M$ from $n=5$ independent experiments $F_{(160}=21.9 ;{ }^{*} p \leq 0.05,{ }^{* *} p \leq 0.01,{ }^{* * *} p \leq 0.001$ one-way ANOVA with Tukey's multiple-comparison test. $\boldsymbol{D}$, Histogram depicting the size distribution of the neurospheres generated from the Prominin- $1^{\text {mid }}$ and Prominin- $1^{\text {low }}$ populations. Data represent the mean \pm SEM from $n=5$ independent experiments, two-way ANOVA no significant effect of population $F_{(8)}=0.13, p=0.73$. 
terized them using flow cytometry. Interestingly, the four Prominin-1 subpopulations each displayed very specific expression profiles for these markers. The Prominin- $1^{\text {high }}$ population contained no $\mathrm{GFAP}^{+} \mathrm{CD} 24^{-}$ cells, but instead $\sim 35 \% \mathrm{GFAP}^{-} \mathrm{CD} 24^{\text {low }}$ cells (Fig. 6A). The Prominin- ${ }^{\text {mid }}$ population in contrast, contained $12 \%$ (Fig. $6 B$ ) and the Prominin- $1^{\text {low }}$ population $11 \%$ $\mathrm{GFAP}^{+} \mathrm{CD} 24^{-}$cells (Fig. $6 \mathrm{C}$ ), but only a small number of $\mathrm{GFAP}^{-} \mathrm{CD} 24^{\text {low }}$ cells (6 and $8 \%$, respectively). Similar to the Prominin- $1^{\text {high }}$ fraction, the Prominin- ${ }^{\text {neg }}$ population contained very few $\mathrm{GFAP}^{+} \mathrm{CD} 24^{-}$ cells (1\%; Fig. 6D). Together, these data supported our in vitro findings that the putative stem cell population $\left(\mathrm{GFAP}^{+} \mathrm{CD} 24^{-}\right.$) can be found in the population of cells with medium-to-low levels of Prominin-1 expression. Additionally, we sorted cells on the basis of these three markers and collected four populations $\left(\mathrm{GFAP}^{+}\right.$Prominin$1^{+} \mathrm{CD} 24^{-}$, $\mathrm{GFAP}^{+}$Prominin- ${ }^{-} \mathrm{CD} 24^{-}$, GFAP ${ }^{-}$Prominin- ${ }^{-}{ }^{-}$D2 $24^{-}$, and GFAP${ }^{-}$Prominin- ${ }^{+/-} \mathrm{CD} 24^{\text {low }}$ ) and again cultured these as neurospheres. As expected the majority of the neurosphere-forming activity was found in the GFAP ${ }^{+}$Prominin$1^{+} \mathrm{CD} 24^{-}$population $(86.2 \pm 5.0 \%$ of total neurosphere number; $n=3$ experiments).

\section{Prominin-1 ${ }^{\text {mid/low }}$ expression marks neural stem cells}

We next confirmed that the Prominin- $1^{+}$ cells could also be cultured efficiently as adherent monolayer cultures (Babu et al., 2007). Prominin-1 ${ }^{\text {high }}$, Prominin $-1^{\text {mid }}$, Prominin- $1^{\text {low }}$, and Prominin- $1^{\text {neg }}$ cells were sorted and each population was plated into a single PDL/laminin-coated well and cultured. In agreement with the results generated from the neurosphere assays, cell proliferation was observed only from the Prominin -1 mid (Fig. 7A) and Prominin-1 ${ }^{\text {low }}$ cultures, whereas no growth occurred from the Prominin- $1^{\text {high }}$ or Prominin- $1^{\text {neg }}$ cells (Fig. $7 B$ ). After having been kept under proliferation conditions for four passages, $>95 \%$ of cells were positive for Nestin and Sox 2 indicating that they have maintained their immunohistochemical stem cell properties (Fig. 7C).

Marker expression and sphere-forming capability supported the idea that a fraction of the Prominin- $1^{+}$cells act as precursor cells. The next question was, whether they also met the specific criteria for stem cells. To examine which neurospheres were stem cell derived, we assessed multipotentiality and self-renewal. We first examined multipotentiality by differentiating the primary neurospheres generated from the Prominin-1-expressing cells in the absence of mitogens for $7 \mathrm{~d}$, followed by staining with the neuronal markers $\beta$ III-tubulin and Map2ab, the oligodendrocyte marker O4, and the astrocyte marker GFAP. This study revealed that while the majority of the neurospheres generated only glia, a small number of them gave rise to all three cell types (Fig. $7 D-F$ ). Quantification of the percentage of $\beta$-tubulin ${ }^{+}$neurons, $\mathrm{GFAP}^{+}$astrocytes, and $\mathrm{O}^{+}$ oligodendrocytes revealed no significant difference in the differentiation potential between the Prominin- $1^{\text {mid }}$ - and Prominin- $1^{\text {low }}$

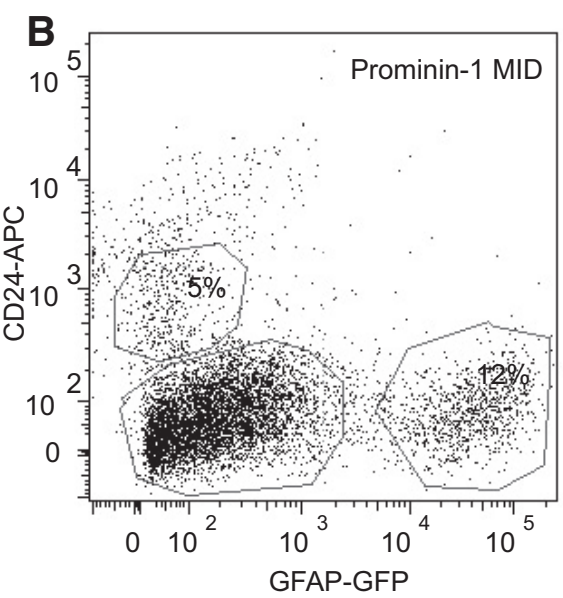

D

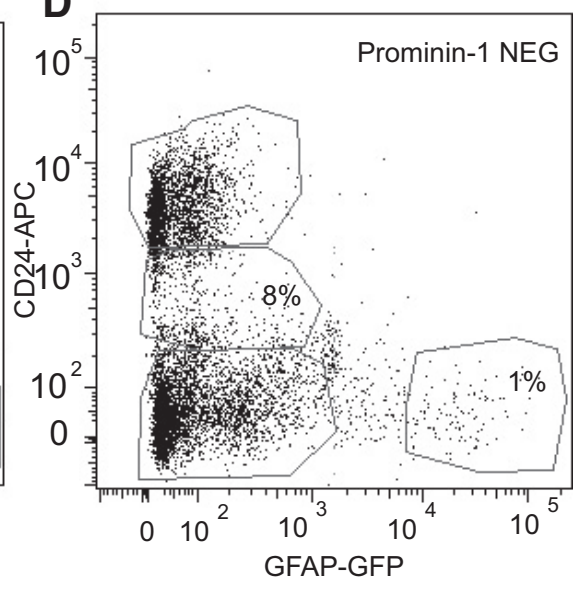

Figure 6. Cells with the highest levels of Prominin- 1 are GFAP ${ }^{-} / \mathrm{CD}_{2} 4^{\text {low }}$. The Prominin-1 ${ }^{\text {high }}$, Prominin- ${ }^{\text {mid }}$, Prominin- $1^{\text {low }}$, other populations, a large proportion $(35 \%)$ of the Prominin- $1^{\text {high }}$ cells were GFAP $-/ \mathrm{CD}_{2} 4^{\text {low }}(\boldsymbol{A})$. In contrast to the Prominin$1^{\text {high }}$ population that contained no GFAP ${ }^{+}$cells, the Prominin- $1^{\text {mid }}$ and Prominin- $1^{\text {low }}$ populations consisted of $\sim 12 \%$ GFAP ${ }^{+}$ cells $(\boldsymbol{B}, \boldsymbol{C})$. Similar to the Prominin- $1^{\text {high }}$ cells, the Prominin- $1^{\text {neg }}$ population contained no GFAP ${ }^{+}$astrocytes/precursor cells $(\boldsymbol{D})$.

derived neurospheres (Prominin-1 ${ }^{\text {mid }}: 8.9 \pm 0.7 \%$ neurons, $69.3 \pm$ $2.8 \%$ astrocytes, $1.9 \pm 0.4 \%$ oligodendrocytes vs Prominin- $1^{\text {low }}$ : $7.4 \pm 2.0 \%$ neurons, $68.9 \pm 3.6 \%$ astrocytes, $1.9 \pm 0.3 \%$ oligodendrocytes; no significant effect of cell population on differentiation potential in a two-way ANOVA $F\left({ }_{77,1}\right)=0.18, p=0.67, n \geq 14$ ). To examine their self-renewal capacity, individual large $(>200 \mu \mathrm{m})$ primary neurospheres were dissociated into single cells, replated into neurosphere medium, and cultured as individual cell lines. This process was repeated every $10 \mathrm{~d}$ up to passage number five after which the number of lines that could be maintained was recorded. Consistent with our previous data (Walker et al., 2008), a small number of these primary neurospheres could be maintained over five passages (10/67 neurospheres), indicating their propensity for self-renewal.

Additionally, the adherent monolayer cultures generated from the Prominin- $1^{\text {mid }}$ and Prominin- $1^{\text {low }}$ cells were passaged and then differentiated in vitro to examine self-renewal and multipotentiality. Following five passages the cells were plated in differentiation conditions in the absence of mitogens (for $5 \mathrm{~d}$ ), after which they were fixed and stained. Following $5 \mathrm{~d}$ under differentiation conditions, both $\mathrm{GFAP}^{+}$astrocytes and $\beta$ III-tubulin ${ }^{+}$ neurons could be found (Fig. $7 G$ ).

In vivo homing of Prominin- ${ }^{+}$cells

Next we investigated whether isolated Prominin- ${ }^{+}$cells that behaved as precursor cells ex vivo would upon re-implantation 

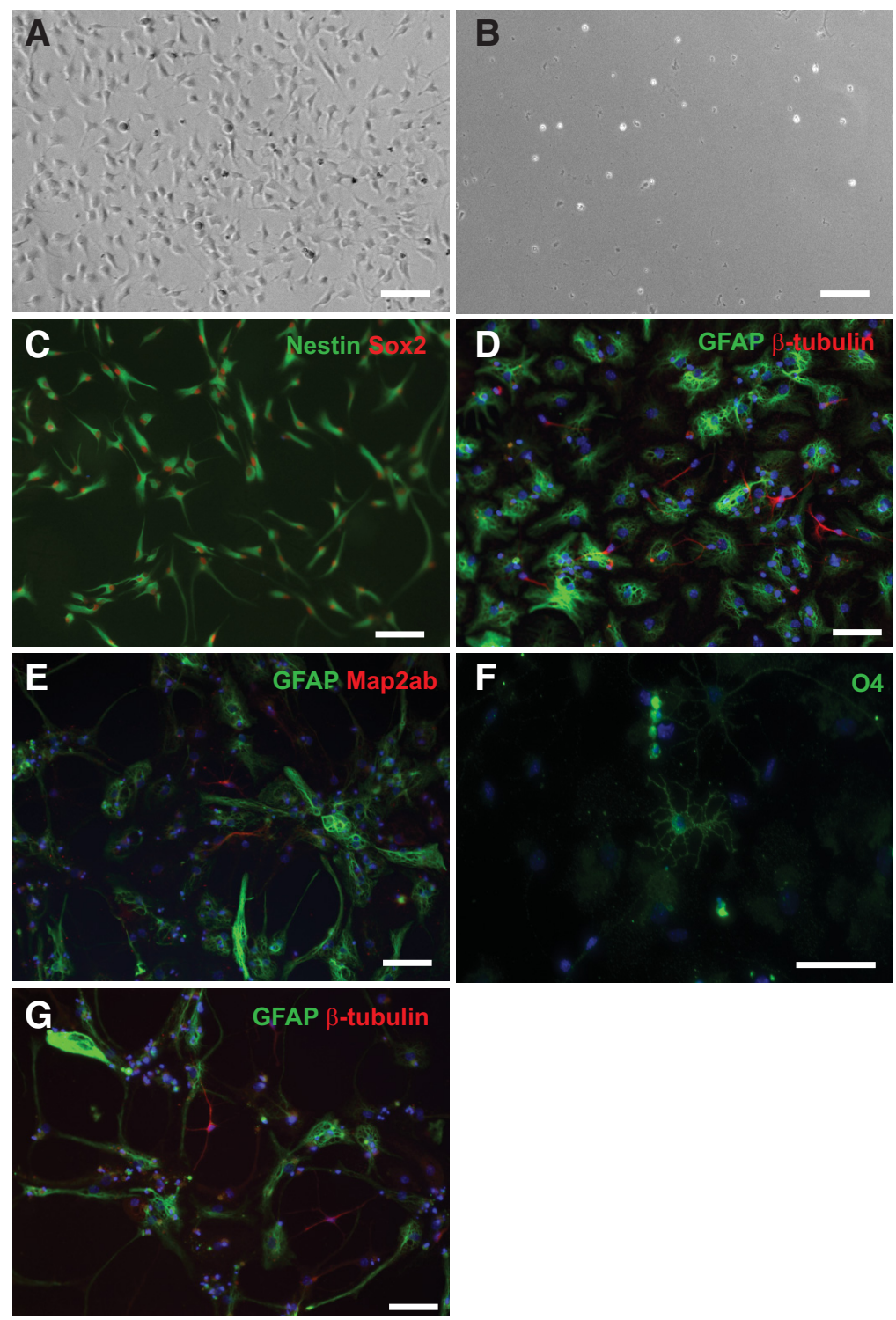

Figure 7. Prominin- $1^{+}$cells are multipotent in vitro. Prominin- $1^{\text {high, mid, low, neg }}$ cells were sorted and then cultured independently as adherent monolayer cultures $(\boldsymbol{A}-\boldsymbol{C}, \boldsymbol{G})$ or neurospheres $(\boldsymbol{D}-\boldsymbol{F})$. Cell proliferation was observed only from the Prominin$1^{\text {mid }}(\boldsymbol{A})$ and Prominin- $1^{\text {low }}$ cultures, with no growth from the Prominin- $1^{\text {high }}(\boldsymbol{B})$ or Prominin- $1^{\text {neg }}$ cells. $\boldsymbol{C}$, After five passages under proliferation conditions the majority of the cells stained positive for the precursor markers Nestin (green) and Sox2 (red) and upon differentiation Prominin- $1^{\text {mid }}$ cells could generate $\mathrm{GFAP}^{+}$astrocytes and $\beta$ III-tubulin ${ }^{+}$neurons $(\mathbf{G})$. Likewise, primary neurospheres generated from the Prominin-1-expressing cells can differentiate into $\beta \mathrm{Ill}_{\text {-tubulin }}{ }^{+}(\boldsymbol{D})$ and Map2ab ${ }^{+}(\boldsymbol{E})$ neurons, GFAP ${ }^{+}$astrocytes $(\boldsymbol{D}, \boldsymbol{E})$, and $04^{+}$oligodendrocytes $(\boldsymbol{F})$. Scale bars: $40 \mu \mathrm{m}$.

show a preference for the neurogenic niche within the SGZ. Prominin- $1^{+}$cells were isolated from the dentate gyrus of $\beta$-actin-GFP reporter mice by flow cytometry using Prominin-1PE. Again, three subpopulations of Prominin-1 were isolated based on its expression level: high, mid, and low. Prominin $-1^{+} /$ $\beta$-actin-GFP ${ }^{+}$cells were then injected directly into the hippocampus of host C57BL/6 mice. Note that sorted primary cells were used immediately after isolation rather than cultured neurospheres to eliminate the possibility that their survival was influenced by exposure to growth factors or extensive culture in vitro. The transplanted mice were kept in environmental enrichment for $6 \mathrm{~d}$ and the fate of the transplanted cells was assessed. Microscopic examination of every third section revealed a small number of bright $\mathrm{GFP}^{+}$cells that had survived in the dentate gyrus (Fig. 8A), the corpus callosum (Fig. 8B), or the hippocam- pal fissure (Fig. 8C). At this stage, these cells were not positive for DCX or GFAP (Fig. 8D), NeuN, NG2, Olig2, A2B5, or Sox2. Fitting with their precursor cell phenotype, the majority of the surviving cells from the Prominin- $1^{\text {mid }}$ and Prominin$1^{\text {low }}$ cell transplantations were located within the SGZ (Prominin-1 ${ }^{\mathrm{mid}}$ : $58.3 \pm$ $30.0 \%$, Prominin- $1^{\text {low }}: 87.5 \pm 12.5 \%$ of total surviving cells per transplantation; Fig. $8 E$ ). This is in contrast to the Prominin- $1^{\text {high }}$ cells, which preferentially survived in the hippocampal fissure $(95.8 \pm 4.2 \% ; n=3$ independent experiments per cell population; significant interaction between cell population and brain region in a two-way ANOVA $F_{(18)}=9.5, p=0.0003$; Fig. $8 E)$.

\section{Knock-out of Prominin-1 affects survival but not proliferation of adult born hippocampal precursor cells} We next determined whether loss of Prominin-1 would specifically affect adult neurogenesis in vivo. Although Prominin- 1 is expressed in a wide range of tissues, its deletion has to date only been shown to cause retinal degeneration (Zacchigna et al., 2009). Gross morphological examination of the hippocampus from Prominin- $1^{-/-}$and Prominin- $1^{+/+}$mice revealed no obvious differences. To determine the effect of Prominin-1 deletion on precursor proliferation in vivo, adult Prominin- $1^{-/-}$, Prominin- ${ }^{+/-}$, and Prominin- $1^{+/+}$mice were given a single intraperitoneal injection of the thymidine analog BrdU and perfused $2 \mathrm{~h}$ later. BrdU immunohistochemistry revealed no difference in the number of $\mathrm{BrdU}^{+}$cells in the SGZ (Prominin-1 ${ }^{-/-}: 2380 \pm 251.6$, $n=4$; Prominin $-1^{+/-}: 2431 \pm 122.3, n=$ 16; Prominin- $1^{+/+} ; 2097 \pm 110.2, n=4$; $F_{(21)}=0.8, p=0.4$; Fig. $\left.9 A, B\right)$ or SVZ (Prominin-1 ${ }^{-l-}: 2746 \pm 151.4, n=4$; Prominin-1 ${ }^{+/-}$: $2573 \pm 96.86, n=16$; Prominin $-1^{+/+} ; 2835 \pm 327.9, n=4$; $F_{(21)}=0.74, p=0.5$; Fig. $\left.9 C, D\right)$ between the three genotypes. Quantification of the number of $\mathrm{DCX}^{+}$intermediate progenitor cells in the SGZ (Type-2b, Type-3, and early postmitotic neurons) also revealed no significant difference between the genotypes (Prominin-1 ${ }^{-1-}$ : $31684 \pm 1762, n=6$; Prominin- $1^{+/-}$: $34123 \pm 661, n=6$; Prominin- ${ }^{+/+}: 29540 \pm 1731, n=4 ; F_{(13)}$ $=2.3, p=0.1$; Fig. $9 E, F)$. In addition, using flow cytometric analysis we compared the numbers of other major cell types in the Prominin-1 ${ }^{-1-}$ dentate gyrus to wild-type controls. These analyses revealed no change in the number of astrocytes $\left(\mathrm{S} 100 \beta^{+}\right.$or $\left.\mathrm{GFAP}^{+}\right)$, oligodendrocytes $\left(\mathrm{Olig} 2^{+}\right)$, neural precursor cells $\left(\right.$ Sox $2^{+}$), or adult-born early postmitotic neurons (Calretinin $^{+}$) between the genotypes (data not shown).

In agreement with the corresponding in vivo proliferation data, there was no difference in the number of neurospheres 
derived from either the dentate gyrus (Prominin-1 $1^{-1-}: 101.2 \pm 17.4, n=5$; Prominin $-1^{+/+} ; 104.0 \pm 10.1, n=5$; twotailed $t$ test $p=0.12$; Fig. $9 G$ ) or SVZ (Prominin-1 ${ }^{-1-}: 1271 \pm 48.1, n=5$; Prominin $-1^{+/+} ; 1481 \pm 124.0, n=5$; two-tailed $t$ test $p=0.15$ ) of Prominin$1^{-/-}$and Prominin $-1^{+/+}$mice.

Interestingly, following depolarization with $\mathrm{KCl}$ in vitro we observed the expected increase in neurosphere number from the Prominin- $1^{+/+}$but no significant increase from the Prominin-1-null mice (Prominin $1^{+/+}: 101.2 \pm 17.4, n=5$ vs $184.8 \pm 12.5 n=5, p=0.003$; Prominin$1^{-/-} ; 104.0 \pm 10.1, n=5$ vs $142.0 \pm 14.1$, $n=5, p=0.25$ one-way ANOVA $F_{(16)}=$ 8.0; Fig. $9 G$ ). The size distribution of the neurospheres generated from the Prominin $-1^{-/-}$and Prominin $-1^{+/+}$mice was also analyzed. The diameter of all neurospheres was measured and classified into four size categories (40-70, 80-120, $130-$ 190 , and $\geq 200 \mu \mathrm{m})$. On this basis we observed no difference in the size distribution of the neurospheres generated between genotype (no significant effect of genotype on neurosphere size in a twoway ANOVA $F(64,3)=0.005, p=0.99$, $n=5$ mice per genotype).

Given that no effects on proliferation in either the SVZ or dentate gyrus could be detected, we were interested to determine whether Prominin-1 deletion affected net neurogenesis. To measure the consequences of net adult neurogenesis in vivo, adult Prominin-1 ${ }^{-1-}$ and Prominin- $1^{+/+}$mice were given a single intraperitoneal injection of BrdU and perfused 28 d later. Interestingly, BrdU immunohistochemistry revealed significantly fewer total BrdU ${ }^{+}$cells in the SGZ of Prominin- $1^{-1-}$ compared with Prominin$1^{+/+}$mice $\left(\mathrm{BrdU}^{+}\right.$cells: Prominin- $1^{-1-}$ : $858.0 \pm 97.6, n=7$; Prominin- $1^{+/+}$: $1244 \pm 81.6, n=8$; two-tailed $t$ test $p=$ $0.009)$. Although there was no significant difference in the percentage of newborn cells that became neurons, as determined by phenotyping $100 \mathrm{BrdU}^{+}$cells for expression of the mature neuron marker NeuN (Fox3; percentage $\mathrm{BrdU}^{+} / \mathrm{Fox}^{+}$: Prominin-1 $1^{-/-}$: $93.2 \pm 1.6 \%, n=7$; Prominin- $1^{+/+} ; 92.7 \pm 1.5 \%$, $n=8$; two-tailed $t$ test $p=0.8$ ), it did, however, result in a significant decrease in net neurogenesis in the Prominin-1 ${ }^{-1-}$ mice (total BrdU ${ }^{+} / \mathrm{Fox}^{+}{ }^{+}$: Prominin- $1^{-1-}: 804.4 \pm 98.3, n=7$; Prominin $-1^{+/+} ; 1157 \pm 85.5, n=8$; two-tailed $t$ test $\left.p=0.02\right)$. In contrast to the dentate gyrus, the deletion of Prominin-1 had no effect on net olfactory bulb neurogenesis (Prominin-1 ${ }^{-1-}$ : $5668 \pm 802.0, n=6$; Prominin $-1^{+/+}: 5591 \pm 353.2, n=7$; twotailed $t$ test $p=0.9$ ) or on the percentage of $\mathrm{BrdU}^{+}$cells that expressed the mature neuron marker Fox3 (Prominin-1 ${ }^{-1-}: 99.3 \pm$ $0.4, n=7$; Prominin- $1^{+/+}: 99.9 \pm 0.1, n=8$; two-tailed $t$ test $p=0.2$ ).
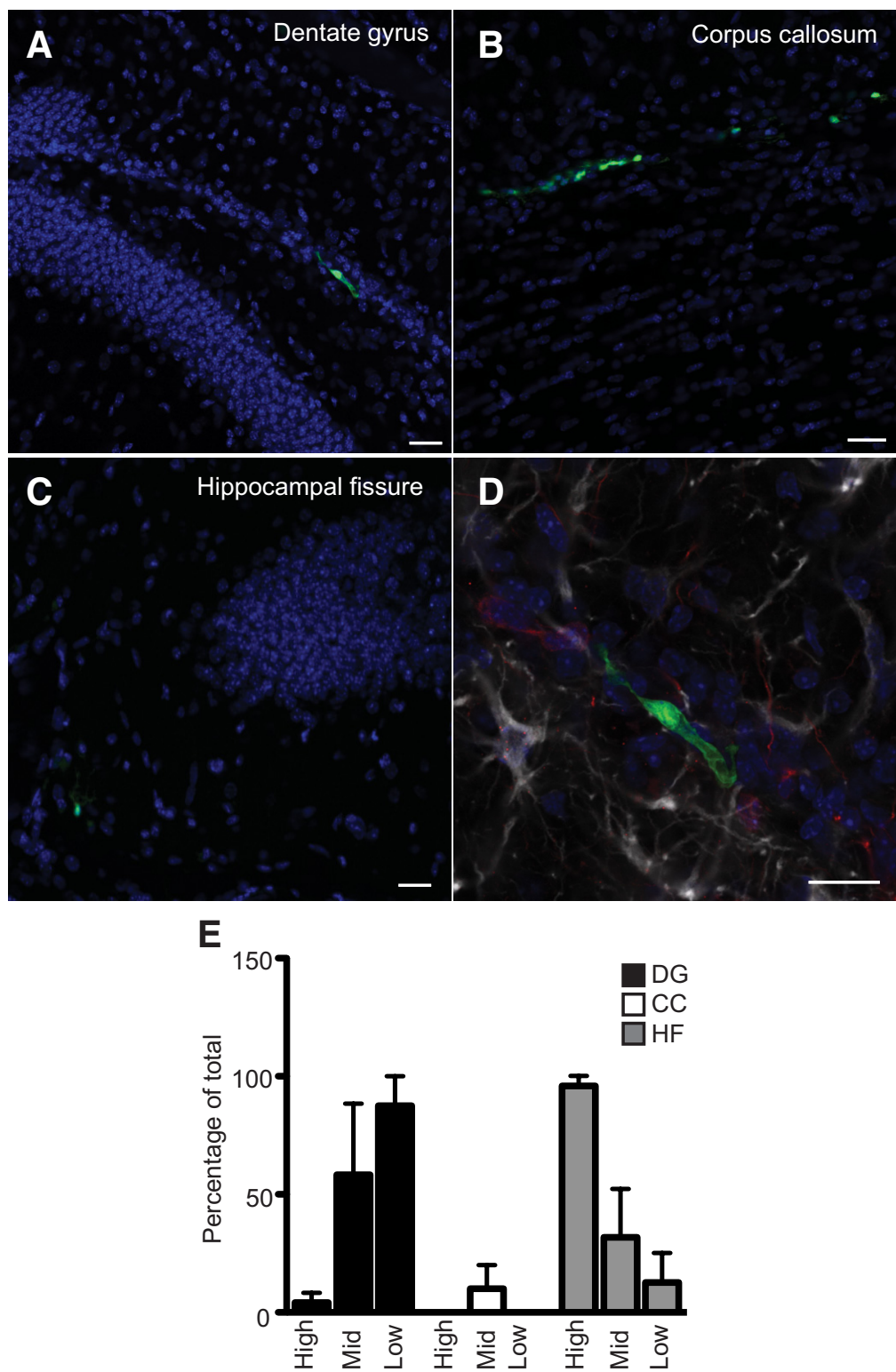

Figure 8. In vivo homing of Prominin- $1^{+}$cells. Six days following the transplantation of primary sorted Prominin $-1^{+} / \beta-$ actin-GFP ${ }^{+}$cells into the adult brain, live GFP ${ }^{+}$cells are localized to the dentate gyrus $(\boldsymbol{A})$, the corpus callosum $(\boldsymbol{B})$, or the hippocampal fissure (C). D, These GFP ${ }^{+}$transplanted cells are not yet positive for DCX (red) or GFAP (white). Scale bars: $20 \mu \mathrm{m}$. $\boldsymbol{E}$, cells migrate to the hippocampal fissure. $n=3$ independent transplantation experiments for each of the cell populations. DG,

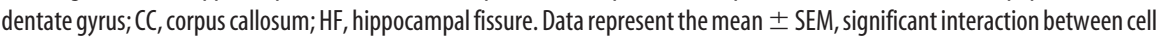
population and brain region in a two-way ANOVA $\left(F_{(18)}=9.5, p=0.0003\right)$.

The Prominin-2 transcript is upregulated in the dentate gyrus of Prominin-1-null mice

Prominin-2 is the second pentaspan membrane glycoprotein that is structurally related to Prominin-1 (Fargeas et al., 2003). Both proteins share a number of important biochemical and morphological properties, including their selective concentration in plasmalemmal protrusions and their association with detergentresistant membranes in a cholesterol-dependent manner (Fargeas et al., 2003; Florek et al., 2007). Therefore, it has been suggested that this may lead to a redundancy in their role as organizers of plasma membrane protrusions (Florek et al., 2007). To test whether, assuming shared functionality, Prominin-2 might compensate for the loss of Prominin-1 in the hippocampal precursor cells of Prominin-1 knock-out mice, we first confirmed 


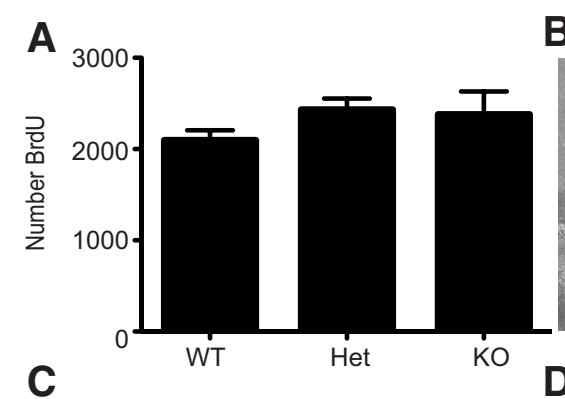

B

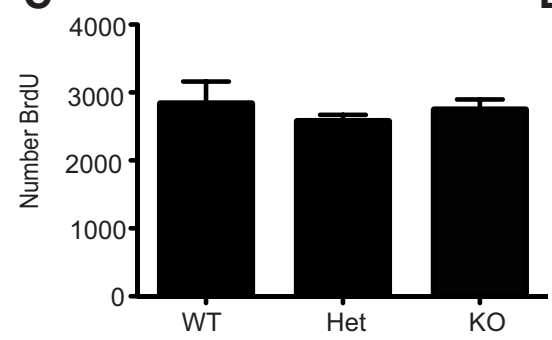

E F

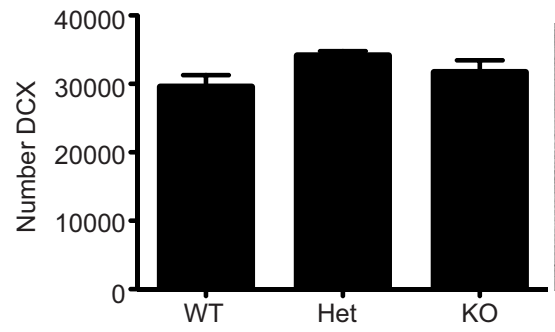

G

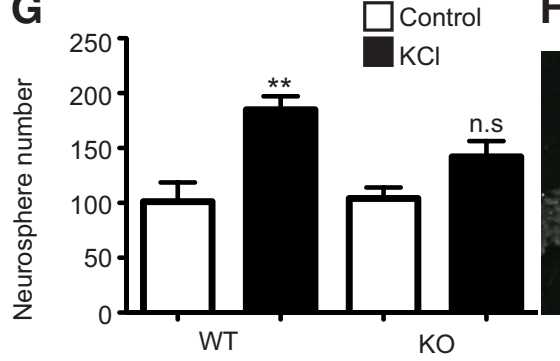

H
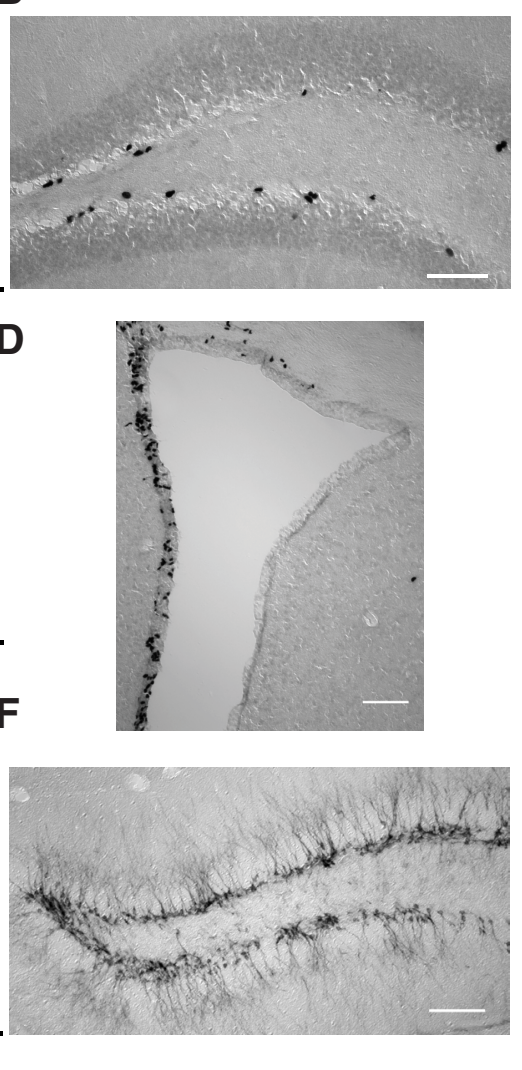

(1)

\section{Discussion}

Despite the large body of literature on Prominin-1 in other brain regions (Weigmann et al., 1997; Corti et al., 2007; Pfenninger et al., 2007), there was very little information on Prominin-1 in the adult SGZ. In this study, we show that neural stem cells in the dentate gyrus of adult mice express Prominin-1, which is consistent with our earlier data showing a genetic association between its expression and neurogenesis in the adult hippocampus (Kempermann et al., 2006).

Our findings suggest that Prominin-1 expression and function in the SGZ might be similar to, but also differ from, other compartments. To further address such tissue compartmentalization, we evaluated which murine splice variants were expressed. We identified Prominin-1 splice variants, in which the small facultative exon at the $\mathrm{N}$-terminal domain is present (s2) or absent (s1), in both the SVZ and SGZ. Likewise, we could amplify a product potentially corresponding to the C-terminal domain of the 33 from the dentate gyrus, although this primer set could not differentiate among the $s 3$, s4, and s5. Given that $s 4$ and s5 variants do not traffic out of the endoplasmic reticulum upon ectopic expression (Fargeas et al., 2004), our data suggest that s3 is indeed found in the dentate gyrus. In contrast, the $\mathrm{s} 6$ variant is found solely in the SVZ but not the SGZ. The ependymal cells where a high level of Prominin-1 is detected may express this splice variant.

In addition to detection of Prominin-1 transcripts, we also localized Prominin-1 protein in the adult SGZ in vivo. As described for other somatic stem cells in different organ systems, the expression of Prominin-1 allowed us to isolate potential precursor cells from the adult hippocampus. Upon dissociation and flow cytometry three distinct cell populations were classified according to their levels of Prominin-1 immunoreactivity levels. Interestingly, those cells with mid-to-low levels of Prominin-1 contained the precursor cells, while the cell fraction with the

the expression of Prominin-2 mRNA in the dentate gyrus. Reverse transcriptase PCR analysis with Prominin-2-specific primers (Table 1), designed to span an intron to eliminate amplification from genomic DNA, amplified the expected product from the dentate gyrus cDNA (data not shown). Given that Prominin-2 was thus expressed in the proper location, we hypothesized that if Prominin-2 is compensating for the lack of Prominin-1 expression, then the relative expression of Prominin-2 should increase in the Prominin-1-null mice compared with their wild-type counterparts. Indeed, Prominin-2 expression was $\sim 35 \%$ higher in the Prominin-1-null mice compared with their wild-type littermates $(135.4 \pm 10.7 \%, t$ test $p=0.03, n=6$ mice per genotype). highest level of Prominin-1 was devoid of precursor cells. This is in accordance with a previous report that embryonic day 13.5 mouse cortical cells with low levels of Prominin-1 could be identified as multipotent stem cells, whereas those with the highest levels were neuronal progenitor cells (Panchision et al., 2007). From the total number of Prominin- $1^{+}$cells only 1 of 115 formed a neurosphere. In contrast, $\sim 1$ of 70 cells in the Prominin- ${ }^{\text {mid }}$ and 1 of 35 cells from the Prominin- $1^{\text {low }}$ populations generated a neurosphere. To further purify the precursor population, Prominin-1 staining was performed on Nestin-GFP transgenic mice (Yamaguchi et al., 2000). Despite the extensive 
characterization of the Nestin ${ }^{+}$hippocampal cells in this transgenic line (Sawamoto et al., 2001b; Filippov et al., 2003; Fukuda et al., 2003; Kempermann et al., 2003; Kronenberg et al., 2003) and their use to isolate precursor cells from brain tissue (Sawamoto et al., 2001a), there have not been any reports on using this mouse to specifically extract precursor cells from the hippocampus. We isolated Nestin-GFP ${ }^{+}$cells by flow cytometry and demonstrated that Nestin is not specific for the Type- 1 and Type-2a precursor cells when used alone. In our hands only 1 of $30 \mathrm{Nestin}^{+}$cells formed a neurosphere in vitro. However, by combining Prominin-1 staining with Nestin-GFP expression we enriched for the precursor cells by removing over half of the nonneurosphere-forming cells that are Nestin ${ }^{+}$but Prominin- ${ }^{-}$, increasing the purity twofold to $\sim 1$ of 14 cells. From the Prominin $-1^{+} /$Nestin ${ }^{+}$population we could generate self-renewing, multipotent neurospheres that differentiated into the three neural lineages, thereby satisfying the cardinal criteria of stemness. In addition, cell cycle analysis revealed that a large proportion of these cells were actively dividing.

Despite the fact that the precursor cells of the adult dentate gyrus express Prominin-1, its expression was not limited to the precursor cells in vivo. FACS analysis revealed that a large number of the Prominin- $1^{+}$cells expressed the common astrocyte markers $S 100 \beta$, GFAP, and GLAST as well as the intermediate progenitor cell marker DCX. In the SVZ, the majority of the Prominin- $1^{+}$cells are ependymal cells ( $\sim 90 \%$ expressed the markers $S 100 \beta$ and the cilia-associated protein acetylated tubulin) and, in addition, this population was reported to contain neither neuroblasts nor transiently amplifying cells (Beckervordersandforth et al., 2010). In the SGZ a quite different situation became evident. In contrast to the SVZ, the dentate gyrus contains no multiciliated ependymal cells but many cells types have been reported to have cilia including both the stem cells (Breunig et al., 2008) and mature neurons (Kumamoto et al., 2012).

To gain insight into the major cell types constituting each of the Prominin-1 populations in the SGZ we used a similar approach to that previously used for the SVZ (Pastrana et al., 2009). We saw very different expression profiles for the GFAP-GFP and CD24 markers in the Prominin-1 populations. Interestingly, in contrast to the ependymal cells of the SVZ $\left(\mathrm{GFAP}^{-} \mathrm{CD} 24^{\text {high }}\right)$, the cells with the highest levels of Prominin-1 expression were $\mathrm{GFAP}^{-} \mathrm{CD} 24^{\text {low }}$, a marker combination that in the SVZ is considered to identify neuroblasts (or "A-cells"). No strict equivalent to this cell type exists in the SGZ and the onset of CD24 expression during neuronal development is unknown. However, CD24 is expressed by differentiating neurons in the adult hippocampus and CD24-deficient mice show increased precursor cell proliferation and adult hippocampal neurogenesis (Belvindrah et al., 2002), suggesting that CD24 might negatively regulate precursor cell proliferation. The highly proliferative precursor cells (Type-2a and -2b) should, accordingly, have low levels of CD24. The Type-1 stem cells of the SGZ express high levels of GFAP, whereas the Type-2a cells have low or absent GFAP expression. In contrast to the Prominin- $1^{\text {high }}$ and Prominin- ${ }^{\text {neg }}$ populations, which contained virtually no $\mathrm{GFAP}^{+} \mathrm{CD} 24^{-}$cells, the Prominin$1{ }^{\mathrm{mid} / \mathrm{low}}$ populations contained a large number of this cell type. The Prominin- $1^{\mathrm{mid} / \mathrm{low}}$ cells that are $\mathrm{GFAP}{ }^{+} \mathrm{CD} 24^{-}$contain astrocytes-a small proportion of which are the $\mathrm{GFAP}^{+}$stem cells. As expected the precursor activity was found only in this $\mathrm{GFAP}^{+}$Prominin ${ }^{+} \mathrm{CD} 24^{-}$subpopulation.

Although a panel of specific cell-surface markers is available for the purification of hematopoietic stem cells, the development of markers capable of identifying and isolating defined neural stem cell populations lags behind. Despite the fact that neurogenesis in the hippocampus is well characterized with respect to the expression of characteristic antigens there seems to be a distinct lack of appropriate surface markers for the isolation of the resident stem cells. There have been only a few reports all of which made use of transgenic reporter mice, i.e., DCX-GFP (Walker et al., 2007), Hes5-GFP (Jhaveri et al., 2010), Nestin-GFP (Gao et al., 2008), Sox2-EGFP (Brazel et al., 2005), and Sox-2-GFP/DCXDsRed (Bracko et al., 2012). The identification of surface markers is important to reduce the dependence on reporter mouse lines, allowing specific cell populations to be isolated from any mouse strain, including transgenic or knock-out mouse models, and the translation of the technology to other species such as rats or humans.

Although Prominin-1 is expressed by the stem cells of the adult SGZ, its absence in Prominin-1 knock-out mice had no obvious effect on precursor cell proliferation. Interestingly, however, we found a significant reduction in the number of new neurons surviving in the Prominin-1 knock-out mice. This is in accordance with previous studies showing that Prominin-1 knockdown does not affect proliferation of colon cancer cells in vitro (Horst et al., 2009) but may be important in for the survival of the tumor seeding cells (Canis et al., 2012). Effects of Prominin-1 on apoptosis were excluded given that no difference was observed in the cleavage of caspase-3 (Horst et al., 2009). It is likely that the closely related family member Prominin-2 compensates for the loss of Prominin-1 as its mRNA expression was upregulated in the hippocampus of Prominin-1 knock-out mice. This situation is particularly interesting since the loss of Prominin-1 in the murine retina, which leads to blindness, is not compensated by Prominin-2 (Zacchigna et al., 2009). Moreover, the absence of Prominin-2 in normal retina (Fargeas et al., 2003) might explain the predominant retinal phenotypes observed in individuals carrying mutations in the Prom 1 gene (Jászai et al., 2007; Arrigoni et al., 2011). To confirm this would require the generation of Prominin-1/Prominin-2 double knock-out mice or a Prominin-2 floxed mouse to delete Prominin-2 specifically in the adult brain of Prominin-1-deficient mice. Those experiments are ongoing.

In summary, we have shown that the cell-surface antigen Prominin-1 can be used to enrich precursor cells from the adult murine dentate gyrus. In addition, we have described novel marker combinations (Nestin/Prominin-1 and GFAP-GFP/Prominin-1/CD24) for the simultaneous flow cytometric isolation of multiple cell types from the adult SGZ. This approach will facilitate the isolation and characterization of homogeneous cell populations of astrocytes, neural precursor cells, and immature neurons to gain a deeper understanding of the underlying molecular regulation of hippocampal neurogenesis in response to activity or injury in individual cell types rather than at the level of the entire dentate gyrus.

\section{References}

Arrigoni FI, Matarin M, Thompson PJ, Michaelides M, McClements ME, Redmond E, Clarke L, Ellins E, Mohamed S, Pavord I, Klein N, Hunt DM, Moore AT, Halcox J, Sisodiya SM (2011) Extended extraocular phenotype of PROM1 mutation in kindreds with known autosomal dominant macular dystrophy. Eur J Hum Genet 19:131-137. CrossRef Medline

Babu H, Cheung G, Kettenmann H, Palmer TD, Kempermann G (2007) Enriched monolayer precursor cell cultures from micro-dissected adult mouse dentate gyrus yield functional granule cell-like neurons. PLoS ONE 2:e388. CrossRef Medline

Barraud P, Thompson L, Kirik D, Björklund A, Parmar M (2005) Isolation and characterization of neural precursor cells from the Soxl-GFP reporter mouse. Eur J Neurosci 22:1555-1569. CrossRef Medline 
Beckervordersandforth R, Tripathi P, Ninkovic J, Bayam E, Lepier A, Stempfhuber B, Kirchhoff F, Hirrlinger J, Haslinger A, Lie DC, Beckers J, Yoder B, Irmler M, Götz M (2010) In vivo fate mapping and expression analysis reveals molecular hallmarks of prospectively isolated adult neural stem cells. Cell Stem Cell 7:744-758. CrossRef Medline

Belvindrah R, Rougon G, Chazal G (2002) Increased neurogenesis in adult mCD24-deficient mice. J Neurosci 22:3594-3607. Medline

Bracko O, Singer T, Aigner S, Knobloch M, Winner B, Ray J, Clemenson GD Jr, Suh H, Couillard-Despres S, Aigner L, Gage FH, Jessberger S (2012) Gene expression profiling of neural stem cells and their neuronal progeny reveals IGF2 as a regulator of adult hippocampal neurogenesis. J Neurosci 32:3376-3387. CrossRef Medline

Brazel CY, Limke TL, Osborne JK, Miura T, Cai J, Pevny L, Rao MS (2005) Sox2 expression defines a heterogeneous population of neurosphereforming cells in the adult murine brain. Aging Cell 4:197-207. CrossRef Medline

Breunig JJ, Sarkisian MR, Arellano JI, Morozov YM, Ayoub AE, Sojitra S, Wang B, Flavell RA, Rakic P, Town T (2008) Primary cilia regulate hippocampal neurogenesis by mediating sonic hedgehog signaling. Proc Natl Acad Sci U S A 105:13127-13132. CrossRef Medline

Canis M, Lechner A, Mack B, Zengel P, Laubender RP, Koehler U, Heissmeyer $\mathrm{V}$, Gires O (2012) CD133 induces tumour-initiating properties in HEK293 cells. Tumour Biol.

Ciccolini F, Mandl C, Hölzl-Wenig G, Kehlenbach A, Hellwig A (2005) Prospective isolation of late development multipotent precursors whose migration is promoted by EGFR. Dev Biol 284:112-125. CrossRef Medline

Corbeil D, Joester A, Fargeas CA, Jászai J, Garwood J, Hellwig A, Werner HB, Huttner WB (2009) Expression of distinct splice variants of the stem cell marker prominin-1 (CD133) in glial cells. Glia 57:860-874. CrossRef Medline

Corti S, Nizzardo M, Nardini M, Donadoni C, Locatelli F, Papadimitriou D, Salani S, Del Bo R, Ghezzi S, Strazzer S, Bresolin N, Comi GP (2007) Isolation and characterization of murine neural stem/progenitor cells based on Prominin-1 expression. Exp Neurol 205:547-562. CrossRef Medline

Ettinger AW, Wilsch-Bräuninger M, Marzesco AM, Bickle M, Lohmann A, Maliga Z, Karbanov á J, Corbeil D, Hyman AA, Huttner WB (2011) Proliferating versus differentiating stem and cancer cells exhibit distinct midbody-release behaviour. Nat Commun 2:503. CrossRef Medline

Fargeas CA, Florek M, Huttner WB, Corbeil D (2003) Characterization of prominin-2, a new member of the prominin family of pentaspan membrane glycoproteins. J Biol Chem 278:8586-8596. CrossRef Medline

Fargeas CA, Joester A, Missol-Kolka E, Hellwig A, Huttner WB, Corbeil D (2004) Identification of novel Prominin-1/CD133 splice variants with alternative C-termini and their expression in epididymis and testis. J Cell Sci 117:4301-4311. CrossRef Medline

Fargeas CA, Huttner WB, Corbeil D (2007) Nomenclature of prominin-1 (CD133) splice variants-an update. Tissue Antigens 69:602-606. CrossRef Medline

Filippov V, Kronenberg G, Pivneva T, Reuter K, Steiner B, Wang LP, Yamaguchi M, Kettenmann H, Kempermann G (2003) Subpopulation of nestin-expressing progenitor cells in the adult murine hippocampus shows electrophysiological and morphological characteristics of astrocytes. Mol Cell Neurosci 23:373-382. CrossRef Medline

Florek M, Bauer N, Janich P, Wilsch-Braeuninger M, Fargeas CA, Marzesco AM, Ehninger G, Thiele C, Huttner WB, Corbeil D (2007) Prominin-2 is a cholesterol-binding protein associated with apical and basolateral plasmalemmal protrusions in polarized epithelial cells and released into urine. Cell Tissue Res 328:31-47. CrossRef Medline

Fukuda S, Kato F, Tozuka Y, Yamaguchi M, Miyamoto Y, Hisatsune T (2003) Two distinct subpopulations of nestin-positive cells in adult mouse dentate gyrus. J Neurosci 23:9357-9366. Medline

Gao X, Enikolopov G, Chen J (2008) Direct isolation of neural stem cells in the adult hippocampus after traumatic brain injury. J Neurotrauma 25: 985-995. CrossRef Medline

Hagihara H, Toyama K, Yamasaki N, Miyakawa T (2009) Dissection of hippocampal dentate gyrus from adult mouse. J Vis. Exp 17; pii:1543. Medline

Horst D, Scheel SK, Liebmann S, Neumann J, Maatz S, Kirchner T, Jung A (2009) The cancer stem cell marker CD133 has high prognostic impact but unknown functional relevance for the metastasis of human colon cancer. J Pathol 219:427-434. CrossRef Medline
Imura T, Nakano I, Kornblum HI, Sofroniew MV (2006) Phenotypic and functional heterogeneity of GFAP-expressing cells in vitro: differential expression of LeX/CD15 by GFAP-expressing multipotent neural stem cells and nonneurogenic astrocytes. Glia 53:277-293. CrossRef Medline

Jászai J, Fargeas CA, Florek M, Huttner WB, Corbeil D (2007) Focus on molecules: prominin-1 (CD133). Exp Eye Res 85:585-586. CrossRef Medline

Jhaveri DJ, Mackay EW, Hamlin AS, Marathe SV, Nandam LS, Vaidya VA, Bartlett PF (2010) Norepinephrine directly activates adult hippocampal precursors via beta3-adrenergic receptors. J Neurosci 30:2795-2806. CrossRef Medline

Kempermann G (2011) Adult neurogenesis 2: stem cells and neuronal development in the adult brain. New York: Oxford UP.

Kempermann G, Gast D, Kronenberg G, Yamaguchi M, Gage FH (2003) Early determination and long-term persistence of adult-generated new neurons in the hippocampus of mice. Development 130:391-399. CrossRef Medline

Kempermann G, Chesler EJ, Lu L, Williams RW, Gage FH (2006) Natural variation and genetic covariance in adult hippocampal neurogenesis. Proc Natl Acad Sci U S A 103:780-785. CrossRef Medline

Kronenberg G, Reuter K, Steiner B, Brandt MD, Jessberger S, Yamaguchi M, Kempermann G (2003) Subpopulations of proliferating cells of the adult hippocampus respond differently to physiologic neurogenic stimuli. J Comp Neurol 467:455-463. CrossRef Medline

Kumamoto N, Gu Y, Wang J, Janoschka S, Takemaru K, Levine J, Ge S (2012) A role for primary cilia in glutamatergic synaptic integration of adultborn neurons. Nat Neurosci 15:399-405, S1. CrossRef Medline

Kuo TC, Chen CT, Baron D, Onder TT, Loewer S, Almeida S, Weismann CM, Xu P, Houghton JM, Gao FB, Daley GQ, Doxsey S (2011) Midbody accumulation through evasion of autophagy contributes to cellular reprogramming and tumorigenicity. Nat Cell Biol 13:1214-1223. CrossRef Medline

Lee A, Kessler JD, Read TA, Kaiser C, Corbeil D, Huttner WB, Johnson JE, Wechsler-Reya RJ (2005) Isolation of neural stem cells from the postnatal cerebellum. Nat Neurosci 8:723-729. CrossRef Medline

Marzesco AM, Janich P, Wilsch-Bräuninger M, Dubreuil V, Langenfeld K, Corbeil D, Huttner WB (2005) Release of extracellular membrane particles carrying the stem cell marker prominin-1 (CD133) from neural progenitors and other epithelial cells. J Cell Sci 118:2849-2858. CrossRef Medline

Mignone JL, Kukekov V, Chiang AS, Steindler D, Enikolopov G (2004) Neural stem and progenitor cells in nestin-GFP transgenic mice. J Comp Neurol 469:311-324. CrossRef Medline

Nolte C, Matyash M, Pivneva T, Schipke CG, Ohlemeyer C, Hanisch UK, Kirchhoff F, Kettenmann H (2001) GFAP promoter-controlled EGFPexpressing transgenic mice: a tool to visualize astrocytes and astrogliosis in living brain tissue. Glia 33:72-86. CrossRef Medline

Obermair FJ, Fiorelli R, Schroeter A, Beyeler S, Blatti C, Zoerner B, Thallmair M (2010) A novel classification of quiescent and transit amplifying adult neural stem cells by surface and metabolic markers permits a defined simultaneous isolation. Stem Cell Res 5:131-143. CrossRef Medline

Panchision DM, Chen HL, Pistollato F, Papini D, Ni HT, Hawley TS (2007) Optimized flow cytometric analysis of central nervous system tissue reveals novel functional relationships among cells expressing CD133, CD15, and CD24. Stem Cells 25:1560-1570. CrossRef Medline

Pastrana E, Cheng LC, Doetsch F (2009) Simultaneous prospective purification of adult subventricular zone neural stem cells and their progeny. Proc Natl Acad Sci U S A 106:6387-6392. Medline

Pfenninger CV, Roschupkina T, Hertwig F, Kottwitz D, Englund E, Bengzon J, Jacobsen SE, Nuber UA (2007) CD133 is not present on neurogenic astrocytes in the adult subventricular zone, but on embryonic neural stem cells, ependymal cells, and glioblastoma cells. Cancer Res 67:5727-5736. CrossRef Medline

Rietze RL, Valcanis H, Brooker GF, Thomas T, Voss AK, Bartlett PF (2001) Purification of a pluripotent neural stem cell from the adult mouse brain. Nature 412:736-739. CrossRef Medline

Röper K, Corbeil D, Huttner WB (2000) Retention of prominin in microvilli reveals distinct cholesterol-based lipid micro-domains in the apical plasma membrane. Nat Cell Biol 2:582-592. CrossRef Medline

Sawamoto K, Yamamoto A, Kawaguchi A, Yamaguchi M, Mori K, Goldman SA, Okano H (2001a) Direct isolation of committed neuronal progenitor cells from transgenic mice coexpressing spectrally distinct fluorescent 
proteins regulated by stage-specific neural promoters. J Neurosci Res 65: 220-227. CrossRef Medline

Sawamoto K, Nakao N, Kakishita K, Ogawa Y, Toyama Y, Yamamoto A, Yamaguchi M, Mori K, Goldman SA, Itakura T, Okano H (2001b) Generation of dopaminergic neurons in the adult brain from mesencephalic precursor cells labeled with a nestin-GFP transgene. J Neurosci 21:38953903. Medline

Singh SK, Hawkins C, Clarke ID, Squire JA, Bayani J, Hide T, Henkelman RM, Cusimano MD, Dirks PB (2004) Identification of human brain tumour initiating cells. Nature 432:396-401. CrossRef Medline

Uchida N, Buck DW, He D, Reitsma MJ, Masek M, Phan TV, Tsukamoto AS, Gage FH, Weissman IL (2000) Direct isolation of human central nervous system stem cells. Proc Natl Acad Sci U S A 97:14720-14725. CrossRef Medline

Walker TL, Yasuda T, Adams DJ, Bartlett PF (2007) The doublecortinexpressing population in the developing and adult brain contains multipotential precursors in addition to neuronal-lineage cells. J Neurosci 27: 3734-3742. CrossRef Medline

Walker TL, White A, Black DM, Wallace RH, Sah P, Bartlett PF (2008) La- tent stem and progenitor cells in the hippocampus are activated by neural excitation. J Neurosci 28:5240-5247. CrossRef Medline

Weigmann A, Corbeil D, Hellwig A, Huttner WB (1997) Prominin, a novel microvilli-specific polytopic membrane protein of the apical surface of epithelial cells, is targeted to plasmalemmal protrusions of nonepithelial cells. Proc Natl Acad Sci U S A 94:12425-12430. CrossRef Medline

Yamaguchi M, Saito H, Suzuki M, Mori K (2000) Visualization of neurogenesis in the central nervous system using nestin promoter-GFP transgenic mice. Neuroreport 11:1991-1996. CrossRef Medline

Yu Y, Flint A, Dvorin EL, Bischoff J (2002) AC133-2, a novel isoform of human AC133 stem cell antigen. J Biol Chem 277:20711-20716. CrossRef Medline

Zacchigna S, Oh H, Wilsch-Bräuninger M, Missol-Kolka E, Jászai J, Jansen S, Tanimoto N, Tonagel F, Seeliger M, Huttner WB, Corbeil D, Dewerchin M, Vinckier S, Moons L, Carmeliet P (2009) Loss of the cholesterolbinding protein prominin-1/CD133 causes disk dysmorphogenesis and photoreceptor degeneration. J Neurosci 29:2297-2308. CrossRef Medline 